\title{
Coordinating Contracts as an Instrument of Supply Chain Profit Maximization under Short-Term Financing Necessity *
}

\author{
Irina Berezinets ${ }^{1}$, Tatyana Voronova ${ }^{1}$, Nikolay Zenkevich ${ }^{1}$ and Natalia \\ Nikolchenko ${ }^{2}$ \\ 1 Graduate School of Management, St. Petersburg University \\ Russia, 199004, St. Petersburg, Volkhovskiy per., 3 \\ E-mail: berezinets@gsom.spbu.ru, tatyana.voronova.rus@gmail.com, \\ zenkevich@gsom.spbu.ru \\ 2 LLC GSP-Komplektaciya \\ Russia, 196105, St. Petersburg, Moskovsky av., 139/1 \\ E-mail: nk.nikolchenko@mail.ru
}

\begin{abstract}
In this paper the problem of the supply chain expected profit maximization under the assumption of the short-term financing necessity for one of the supply chain parties using a coordinating contract is considered. The solution is derived for a two-echelon supply chain under the assumption of product demand being distributed as uniformly. A revenue-sharing contract with bank financing and a modified revenue-sharing contract with trade credit financing are explored. It is stated that none of the studied contracts is coordinating, as they do not provide the supplier's expected profit maximum. The conditional coordination of supply chain with a modified revenue-sharing contract with trade credit financing is considered if the supply chain and the retailer's expected profit maximum are reached and the supplier's expected profit is greater than in case of application of a modified wholesale price contract with trade credit financing and a revenue-sharing contract with bank financing. It is proved that it is beneficial for both supply chain parties and the problem of the supply chain expected profit maximization under the assumption of the short-term financing necessity for one of the supply chain parties can be solved using a modified revenue-sharing contract with trade credit financing.
\end{abstract}

Keywords: Supply chain, coordination, coordinating contract, profit, shortterm financing

\section{Introduction}

One of the main drivers of any firm's action is maximization of its own profit, but as a result of such actions it can be a case that the supply chain's profit does not reach its maximum. However, it is possible to maximize the profits of both the supply chain and its parties if the actions of the parties are coordinated in this direction, i.e. with supply chain coordination. One of the most frequently used and studied coordination mechanisms is contracts, as this mechanism allows coordinating the interaction of parties from both operational (material flows) and financial (financial flows) points of view, while remaining practical in application. In recent research literature several main types of contracts are distinguished, the parameters of contracts are the subject of negotiations between the supply chain parties, while

\footnotetext{
* Research has been conducted with financial support from SPbU grant (project No. 48952577)
} 
the algorithms for their optimal values derivation that ensure the supply chain coordination are the subject of studies conducted by researchers.

An essential component of company's activity is the management of financial resources, including the decision-making process on external borrowing. As a supply chain coordination mechanism the contracts are closely related to the determination of financial flows arising between the parties in operational activities, thus, the parameters and conditions of short-term financing of the parties should also be considered when deriving the optimal parameters of the contract. One of the types of short-term financing is a trade credit provided by a counterparty, and the result of considering this aspect of the relationship is not only a change in cash flows (for example, an additional interest payment flow), but also modification of the contract terms themselves by inclusion of such additional parameter as the interest rate of the supplier. Nowadays researchers have a great interest in the field of supply chain coordination under the assumption of the parties being financially constrained, however, the majority of papers ("Trade credit for supply chain coordination", Lee, Rhee (2011), "Financing the Newsvendor: Supplier vs. Bank, and the Structure of Optimal Trade Credit Contracts", Kouvelis, Zhao (2012),"Financing decisions in supply chains with a capital-constrained manufacturer: competition and risk", Shen et al. (2019), etc.) focus on the simplest type of contract - a wholesale-price contract.

The aim of the paper is to solve the problem of the supply chain expected profit maximization under the assumption of the short-term financing necessity for one of the supply chain parties using a coordinating contract. The study considers a twoechelon supply chain. The issue of profit maximization is one of the essential for the general management of the company, while the problem of choosing financial sources and conditions is one of the most important for financial management. The combination of these problems and the subsequently proposed solution, which is based on such counterparties' interaction coordination mechanism as contracts, is of considerable interest. Therefore, the results of this research can be used in decision-making process while choosing the contract parameters to maximize the supply chain profit when short-term financing of one of the supply chain parties is necessary.

The paper is organized as follows. The first part is devoted to the literature review of contracts use as a mechanism of supply chain coordination. The second part contains the study of two types of short-term financing used by companies: a trade credit and a bank credit, and provides a literature review on the impact of the short-term financing necessity for supply chain parties on supply chain coordination using contracts. The third part presents the solution to the problem of the supply chain expected profit maximization under the assumption of the short-term financing necessity for one of the supply chain parties using a coordinating contract and the product demand being distributed as uniformly. The simulated case is used for examination of proposed solution. In conclusion, the results of the study are summed up.

\section{Contract as a Mechanism of Supply Chain Coordination}

Supply chain contracts as a mechanism of coordination is used for better management of relationship and risk management (Arshinder et al., 2011). From the juridical point of view, a contract is an agreement with specific terms between two 
or more persons or entities in which there is a promise to do something in return for a valuable benefit known as consideration. In terms of contractual relations, the parties create mutual obligations enforceable by law. To be a legally enforceable a contract must comprise such basic elements of the agreement like mutual assent, expressed by a valid offer and acceptance; adequate consideration; capacity; and legality. In case of supply chain interactions, the term "contract" comprises such parameters like quality, price, quantity within which a retailer places the order and a supplier fulfills it. Generally, supply chain contracts can be characterized as "interaction rules". Tsay et al. (1999) distinguish three purposes of supply chain contracts: system-wide performance improvement (increase in the total supply chain profit), risk sharing among the supply chain parties, and facilitation of long-term partnerships.

A number of contractual forms have been studied recently, but the most frequently considered types of contracts are the following: wholesale contracts, with the distribution of revenue (revenue-sharing contracts), with buyback, sales-rebate, with a flexible pricing policy (e.g. quantity discount contracts), as well as combined and individually designed contracts. A common "rule" for all studies conducted is the determination of coordinating contract. Research conducted concurs that one of the points in definition of a contract to be coordinating if its implementation leads to the supply chain profit maximization (Wong et al., 2009; Cachon, 2003; Pasternack, 1985). However, if the profit of the chain is maximized, it does not mean that the profits of all participants will attain their maximum. It means that not all supply chain parties will have the incentives which are strong enough to comply with the terms of the contract. That means that it is not enough just to maximize supply chain profit. Some researchers have noted that the profits of the supply chain participants after implementing a coordinating contract must be better than without it. Such situation is called a «win-win» situation (Taylor, 2002; Saha, 2013). Other researchers, using a game-theoretic approach for defining a coordinating contract, model the situation of signing a contract between two chain participants like a twoperson game, the solution of which is a set of such contract parameters that provide Nash equilibrium (Cachon, 2003). Following (Cachon, 2003), researchers Heydari et al., 2017, Heydari and Asl-Najafi, 2018 believe that the contract is coordinating if it allows to maximize the expected profit of the supply chain and using the parameters of the coordinating contract to ensure the Pareto-optimality of the obtained solution. In other words, the coordinating contract should provide the expected profit value to be no worse than without the contract application, and at least one of the participants should be (slightly) better-off (Heydari et al., 2017). Berezinets et al. (2019) define the contract to be coordinating, if the contract parameters allow for the retailer's, supply chain and supplier's profits maximization, in turn the contract is considered as conditionally coordinating if the supplier performs at least as well as without the contract implementation conserving two other points of definition.

\section{Supply chain coordination with a wholesale price contract}

One of the most frequently used and one of the simplest type of contracts which is considered to be a basic one in supply chains is a wholesale price contract. According to this type of contract, a supplier offers a retailer the only parameter - a wholesale price per product unit $\omega$, which is fixed and does not depend on the order volume. In response to the supplier's offer, the retailer decides on the order volume $q$. On the moment of market realization, the retailer sells the product at the retail price $p$ per 
unit. In case of failure of total realization of the purchased volume, the remained product can be sold at the salvage value $\nu$ per unit.

Cachon (2003) states that a wholesale price contract fails to coordinate a supply chain as the problem of double marginalization arises if this type of contract is unilaterally implemented. However, a wholesale price contract can achieve supply chain coordination in combination with a returns policy or returns discount contract (Chen, 2011).

Supply chain coordination with a revenue-sharing contract

Under a revenue sharing mechanism, the transactions between the supplier and the retailer are governed by a share of the retailer's revenue that is received by the supplier at the end of a selling season. According to Giannoccaro and Pontrandolfo (2004), a revenue-sharing contract implies that a supplier offers a retailer the following contract parameters: a wholesale price per product unit $\omega$ that is lower than the production costs and a fixed share of the retailer's revenue $\varphi$, which aims to compensate the losses from low wholesale price. In response to the supplier's offer, the retailer decides on the order volume $q$. On the moment of market realization, the retailer sells the product at the retail price $p$ per unit. In case of failure of total realization of the purchased volume, the remained product can be sold at the salvage value $\nu$ per unit. After that, the retailer transfers the supplier the revenue share $\varphi$.

This approach was one of the first to appear massively in supply chain contractual management practice (besides a wholesale contract) due to a Blockbuster videocassette rent case (Mortimer, 2008). Before the implementation of revenuesharing contract mechanism, Hollywood studios sold videotapes using a traditional wholesale price contract to Blockbuster and other small video retailers for $\$ 65$ per tape, with retailers collecting $\$ 3$ per rental. With the revenue-sharing contract, Blockbuster paid studios $40 \%$ of its rental revenue in exchange for a reduction in the unit wholesale price from $\$ 65$ to $\$ 8$. The contract helped Blockbuster to gain greater market share, while the studios ensured high levels of availability of their videos to customers, thus effectively aligning the interests of supply chain parties.

Cachon and Lariviere (2005) were the first to state that the revenue sharing contract coordinates the supply chain. Moreover, it allows to divide the resulting profits for any reasonable revenue function arbitrarily. Further, it was shown that a buy-back contract is a special case of a revenue-sharing contract when the retail price is fixed. However, a revenue sharing coordinates the supply chains even with the price-dependent demand (Bernstein and Federgruen, 2005), which buybacks cannot (Pasternack, 1985). The drawback of this type of contracts is in great amount of limitations and some researchers (Bernstein and Federgruen, 2005) do not consider it coordinating one. There is the administrative burden imposed on the firms due to this mechanism. Under revenue sharing, the supplier must monitor the retailer's revenues to verify that they are split appropriately. The gains from coordination may not always cover these costs. Moreover, a revenue sharing does not coordinate a supply chain when there is a deviation from the limitations of Stackelberg model, making it inconvenient to apply (Corbett and DeCroix, 1999).

Supply chain coordination with a buyback contract

In assuming of two-echelon supply chain system, the retailer, who often faces uncertainties in demand, typically orders fewer products than the optimal order quantity which negatively affects the supply chain performance. One of the solutions 
to increase the quantity ordered by the retailer is for the supplier to share the inventory risk by offering to buy back the remaining obsolete inventory at a price which is less or equal to the salvage value (Simchi-Levi et al., 2008).

Thus, with a buyback contract, a supplier offers a retailer a wholesale price per product unit $\omega$ and the buyback price $b$ per unit for each unsold item of the order. In response the retailer makes a product order $q$ at the start of the season and have an opportunity to return any quantity of remained units at the end of the season and get a refund, or buy-back, payment. On the moment of market realization, the retailer sells the product at the retail price $p$ per unit.

The literature on the buyback contracts (Pasternack, 1985; Tsay, 1999; Cachon, 2003; Bernstein, 2005; Becker-Peth et al., 2013) traditionally considers two types of buyback contracts depending on the one who sells the stocked products at the end of the season. The first type implies that the retailer returns unsold goods to the supplier for the redemption price $b$ per unit and then the supplier is able to realize these remained items at the salvage value $\nu$ per unit. The second type of buyback contracts implies that the retailer is being paid by the supplier a compensation $b$ per unit for the unsold goods, but the unsold products remain at the retailer and can be sold by him at the end of the season for the salvage value $\nu$ per unit.

Considering buyback contracts most of the researchers (Pasternack, 1985; Wang, 2002; Xiao, Yang, 2010; Xiong, Xie, 2011) state the ability of the buyback to coordinate the supply chain. As previously indicated, buyback contracts are able to coordinate the fixed-price newsvendor (Pasternack 1985) and are equivalent to revenue-sharing contracts under the assumption of a fixed retail price (Cachon and Lariviere 2005). But unlike revenue sharing, the coordinating buyback parameters depend on the retail price. Hence, it is not surprising that in contrast to revenue sharing, buybacks struggle with the price-setting newsvendor. In this case, buyback contract cannot achieve coordination unless the supplier can impose resale price maintenance. In addition, Bernstein and Federgruen (2005) demonstrate that buyback contract coordinates the price-setting newsvendor only if the supplier earns zero profit. Wei and Tang (2013) have analyzed coordination of a Stackelberg game model based on the buyback contract predominated by the supplier, and obtained the Nash equilibrium solution to this model (a situation of coordination of the supply chain following their definition) when wholesale price and maximum buyback price are determined by the supplier and the order quantity is determined by the retailer with respect to the stochastic market demand. The paper has set certain conditions and model constraints that the supplier is in the leading role and he can determine the proportion or relation of risks shared by supply and demand parties. Here we get a conditional coordination. The buyback contract enables supply chain coordination and increases the supply chain profit with a single retailer, but it can be less optimal in a multi-retailer environment (Wang and Zipkin, 2009). Overall, Simchi-Levi et al. (2008) found that the buyback contract decreases the retailer's and increases the supplier's risk. However, adopting the buyback contract involves (over)compensation for the supplier's risk and results in both parties being better off.

Most researches related to the buyback type of contracts are conducted in terms of combined contracts of various combinations and modifications which lead to the contract to be coordinating (Xiong et al., 2011; Qin et al., 2013). The more constraints are made, the easier to construct the coordinating contract. 
Supply chain coordination with a sales-rebate contract

A sales-rebate contract aims to motivate the retailer (in two-echelon system) to sell (and, consequently, to order) more and, as a result, allows to earn an extra rebate for each unit of products sold in excess of the sales volume threshold established by the supplier. According to Wong et al. (2009), the sales-rebate contract motivates the retailer to sell goods at a lower price in order to increase sales volume. Here, a supplier offers a retailer the following contract parameters: a wholesale price per product unit $\omega$ and a rebate $r$ for each unit that the retailer sells above the sales volume threshold $t$ set by the supplier. In response to the supplier's offer, the retailer makes the product order for volume $q$. The retailer sells the product on the market at the retail price $p$ per unit. In case of failure of total realization of the purchased volume, the remained products can be realized at the salvage value $\nu$ per unit. This type of contract is actively used in such industries like hardware, software, and auto ones (Taylor, 2002).

Taylor (2002) was one of the first to consider applying a sales-rebate contract for coordinating a two-echelon supply chain system. According to him, a coordination of the supply chain is understood as the situation in which the supply chain profit would be maximized. Align with the coordination, Taylor considered the possibility of achieving a "win-win" situation in which the expected profit of each participant will be better than without the coordinating contract application. He has allocated two types of rebate: a linear rebate and a target rebate. The linear rebate is paid by the supplier to the retailer for each unit of products sold, while the target rebate is paid only for each unit of product exceeding the set threshold. Taylor (2002) showed that due to the sales-rebate contract, a "win-win" situation and a coordination of the supply chain are achieved (following his definition of coordination), but this is only true for a contract with a target rebate.

Another significant paper contributing to the study of sales-rebate contracts as the solution for the supply chain coordination is Cachon (2003). The author applied a game-theoretic approach and defined the contract to be coordinating if the chosen parameters of this contract provide Nash equilibrium. In contradiction to Taylor (2002) Cachon proves that the sales-rebate contract does not allow coordinating supply chain, since the supplier will lose money for each unit of goods sold by the retailer in excess of the established sales threshold. The later work of Cachon and Lariviere (2005) and Chiu et al. (2012) justified the possibility of coordinating the supply chain through a sales-rebate contract under certain conditions: the retailer's selling price is fixed, and the volume supplied to the retailer is above the set sales threshold.

Summing up, since different researchers apply different definitions of coordinating contracts, there are no clear and unique conclusions for different types of contracts whether they are coordinating or not, creating a respective research gap.

\section{Forms of Short-Term Financing of Supply Chain Parties and Their Impact on the Contractual Supply Chain Coordination}

The capital structure and especially working capital management decisions have a significant impact on the costs of the company and, as a result, on profit. As the profit is a key measurement used in contractual coordination, the influence of financing decisions on the ability to coordinate the supply chain and contract design is of a great interest. 
In terms of contractual supply chain relationship, we are interested in such area of corporate financing decisions like decisions of short-term financing. It is a common thing that this or that counterparty is temporarily insufficient in internal financing during operational activity and has to use external sources. The main external short-term financing types are trade credit financing and bank credit financing.

Trade credit is a form of delayed payments for the transfer of goods and services in which upstream supplier allows downstream retailer to settle the payments at the end of the sales period. Trade credit has been referred to as one of the important sources of short-term financing for the firms and could play an important role in firms' growth potential, competitive advantage, and survival (Lin and Chou, 2015). The most typical trade credit contract is that of supplier early payment discount. It allows retailers to pay the supplier for products purchased within a given time window, e.g., 30, 60, or 90 days, without incurring financial charges. However, early payment is encouraged through a discount on the offered wholesale price. If there is no early payment discount, the trade credit practice is referred to as open account financing (Kouvelis and Zhao, 2012).

Bank credit financing is another way of short-term financing completing with the attraction of the third party financial intermediary. The overall mechanism differs from the trade credit financing as it includes new level of contractual relationship outside the supply chain relationship. In most cases there is no possibility for the supply chain members to negotiate much about the terms of the credit contract, thus if the bank is not considered as a member of a supply chain, the terms (e.g. time period, interest rate) are considered to be given and fixed (Xiao et al., 2017). The scheme of bank loan receiving is more complicated than the one of a trade credit due to existence of formal requirements and procedures like underwriting and scoring, which make the bank credit financing unavailable for some companies (especially SMEs). There is also a difference in interest rates associated with these two shortterm financing types. In case of repayment failure, the bankruptcy procedures are initiated.

The terms of short-term financing are widely discussed in financial academic literature and corporate finance research papers (Giannetti et al., 2011; Fabbri and Klapper, 2008), but studied individually for a separate company. On the contrary, we are interested in implementation of financial aspects into the supply chain environment.

The majority of articles are concentrated on the retailer being financially constrained. Most of the "financing the newsvendor" researches are built upon this model by adding liquidity constraints and exploring the effectiveness of various financing schemes to alleviate them. An early influential work by Li et al. (2013) (first draft appeared in 1997) discusses a stylized multiperiod dynamic newsvendor model of a capital constrained firm optimizing its shareholders' long-term dividends. The firm borrows necessary bank loans when it makes inventory decisions. The optimal myopic newsvendor decisions are functions of bank's interest rates (i.e., inventory decisions rely on financial terms), which implies the integrated nature of operational and financial decisions. Also, among the first to bring capital constraints within a simple newsvendor model (i.e., analysis of the retailer's stage and not of the overall supply chain) is the work of Xu and Birge (2004). The authors try to understand the impact of capital structure (competitively priced long-term debt versus equity) on the retailer's operational decisions. Kouvelis and Zhao (2012) analyze the Stackel- 
berg game between the supplier and the retailer in the presence of short-term bank credit financing.

Several articles took trade credit as a decision variable from the supplier's or the supply chain's point of view. Kim et al. (1995) and Abad and Jaggi (2003) developed a model to find the optimal credit period for the supplier by taking pricesensitive demand into consideration. Zhou et al. (2012) determined the supplier's credit policy considering inventory-dependent demand and limited displayed-shelf space. However, these studies did not consider the issue of supply chain coordination.

Most previous studies on the role of trade credit and bank credit in coordinating supply chain failed to consider the newsvendor model which is an important mathematical model for uncertain demand. Still there is research conducted which investigated the role of the composite mechanism based on trade credit and other traditional coordinating contracts in supply chain coordination for uncertain demand. Tsao et al. (2017) presented newsvendor models to maximize total profits while taking into account uncertain demand, trade credits, carbon emissions, and the risk of default simultaneously. Cao and $\mathrm{Yu}$ (2018) investigated the financing and coordination of an emission-dependent supply chain by trade credit. Heydari et al. (2017) and Tsao (2017) introduced two-level trade credits into supply chain coordination for uncertain demand.

In recent years, researchers have begun to investigate the problem of supply chain coordination with capital constraints implementing bank credit financing. In terms of financial constraints of the retailer Dada and $\mathrm{Hu}$ (2008) proposed a nonlinear bank loan schedule as a coordination mechanism for the newsvendor only. Lee and Rhee $(2010,2011)$ adopted trade credit for coordinating a supply chain when both the supplier and the retailer are financially constrained. Kouvelis and Zhao (2016) designed supply chain contracts to coordinate the capital-constrained supply chain with bankruptcy costs. The study investigates the issue and designs coordinating contracts when financial constraints and default costs exist. The authors assumed that the supplier as well as the retailer have access to bank financing and only bank financing as an external source of short-term financing is considered. Xiao et al. (2017) proposed the coordination of the newsvendor within a supply chain structure in the presence of default costs either, but assuming that only trade credit is available for the retailer. The same is done by Lee and Rhee (2010), but without considering default costs. Taking trade credit as a mechanism to coordinate a supply chain, Jaber and Osman (2006) studied how to set order quantity and trade credit to minimize the cost of the whole supply chain under constant demand. The majority of researches are done on the basis of a wholesale price contract, except Kouvelis and Zhao (2016) and Xiao et al. (2017), which referred to revenue-sharing and buyback contracts, but the analysis was done only in field of one type of short-term financing: bank financing and trade credit respectively.

\section{Supply Chain Coordination with Revenue-Sharing Contract with Bank Financing under the Assumption that Demand is Distributed as Uniformly}

Financing issues play a crucial role in supply chain management destined for optimization of the availability and cost of capital within a given supply chain. That is why there is a necessity to consider financial parameters while analyzing the interactions of supply chain parties. 
For further modelling a decentralized two-echelon supply chain consisting of one supplier ( $\mathrm{S}, \mathrm{she})$ and one retailer $(\mathrm{R}, \mathrm{he})$ is considered within a single period. A retailer has insufficient volume of cash available for payment flow and in need of short-term financing. For the external short-term financing for the retailer a bank financing and a trade credit financing from the supplier are available at the beginning of the selling period. Regardless the chosen source of short-term financing, the financial constrained party is imputed with the interest rate payment at the end of the selling period. The retailer orders a single type of products from the supplier once prior to the sales season and additional orders or order corrections are not allowed. The supply chain parties have contractual relationships. A modelling of contracts is made using the game-theoretic approach, a contracting process is seen as a two-step game. As a base model Stackelberg model is used assuming the supplier is a leader making the decisions and choosing her strategy first and the retailer is a follower choosing his strategy corresponding to the supplier's in terms of stochastic demand. Here, the leader has an advantage, since she can optimize her target function considering the answer and the function of winning of the follower known in advance.

The following assumptions are held (Table 1).

Table 1. Assumptions for modelling

\begin{tabular}{|c|l|}
\hline$A_{1}:$ & The supplier and retailer are risk neutral; \\
\hline$A_{2}:$ & $\begin{array}{l}\text { The supplier and retailer are rational trying to maximize their } \\
\text { profit values; }\end{array}$ \\
\hline$A_{3}:$ & $\begin{array}{l}\text { The supplier and retailer operate in terms of complete informa- } \\
\text { tion and symmetry of cash available, demand distribution, bank } \\
\text { financing interest rates, and contract (e.g. wholesale price, trade } \\
\text { credit interest rate), production (e.g. costs) and sales (e.g. retail } \\
\text { price) parameters; }\end{array}$ \\
\hline$A_{4}:$ & $\begin{array}{l}\text { The retailer is capital-constrained and may choose either a bank } \\
\text { loan or a trade credit as financing source, the bankruptcy risk is } \\
\text { not considered assuming that the retailer is able to fully cover } \\
\text { his loan obligations at the end of the selling season; }\end{array}$ \\
\hline$A_{5}:$ & $\begin{array}{l}\text { There are no moral hazard issues, i.e. parties have no ex-ante } \\
\text { intention to break the contractual agreement; }\end{array}$ \\
\hline$A_{6}:$ & $\begin{array}{l}\text { The capital market is considered without taxes and transaction } \\
\text { costs. }\end{array}$ \\
\hline
\end{tabular}

For the contract modelling the following notations are used (Table 2). As can be seen further, due to the presence of necessity of external financing for the retailer, it is important to define the time periods of financial flows appear in the supply chain and a discounting factor. Throughout the modeling process a risk-free rate $r_{f}$ is taken as a discounting factor and without the loss of generality it is assumed to be equal to zero. The same assumptions are applied to a salvage value of the product and a goodwill loss. 
Table 2. List of notations

\begin{tabular}{|c|l|}
\hline$\omega$ & The wholesale price per unit (c.u.) \\
\hline$\varphi$ & The supplier's share of the retailer's revenue \\
\hline$q$ & The volume of products vended by the supplier to the retailer (pcs.) \\
\hline$c_{S}$ & The retail price per unit (c.u.) \\
\hline$c_{R}$ & The supplier's production costs per unit (c.u.) \\
\hline$c=c_{R}+c_{S}$ & The retailer's realization costs per unit (c.u.) \\
\hline$K_{R}$ & The retailer's cash available (c.u.) \\
\hline$r_{R}{ }^{B}$ & The retailer's bank interest rate \\
\hline$r_{R} S$ & The retailer's supplier interest rate \\
\hline$\pi_{R}$ & The retailer's profit per transaction (c.u.) \\
\hline$\pi_{S}$ & The supplier's profit per transaction (c.u.) \\
\hline$\pi_{S C}=\pi_{R}+\pi_{S}$ & Supply chain profit per transaction (c.u.) \\
\hline $\mathbb{E}\left[\pi_{R}\right]$ & The retailer's expected profit per transaction (c.u.) \\
\hline $\mathbb{E}\left[\pi_{S}\right]$ & The supplier's expected profit per transaction (c.u.) \\
\hline $\mathbb{E}\left[\pi_{S C}\right]$ & Decentralized supply chain expected profit per transaction (c.u.) \\
\hline
\end{tabular}

The demand for the product is assumed to be stochastic. Let $\xi$ denote demand and let $\tau$ denote the volume of this product sold. $\xi$ is a continuous random variable with probability density function $f_{\xi}(x)$ and strictly increasing and differentiable probability distribution function $F_{\xi}(x)$. Let $\tau=g(\xi)$, where

$$
\tau=g(\xi)=\left\{\begin{array}{l}
\xi, 0 \leq \xi<q \\
q, \xi \geq q
\end{array}\right.
$$

Time $t=0$ : based on the decision of retailer to use a bank financing, at the first step the supplier offers the retailer the following contract parameters: the wholesale price per unit $(\omega)$ and a share of the retailer's revenue $(\varphi)$ which the retailer must transfer to the supplier at the end of the sales season. Considering the suppliers' conditions offered, the retailer decides on the quantity of goods $(q)$ he should order to maximize his profit based on the market demand information. After signing the contract, the retailer borrows the sum needed considering the cash available $\left(K_{R}\right)$, costs for realization $\left(c_{R} q\right)$ and supplier's wholesale price payment $(\omega q)$. Subsequently, the wholesale price payment is transferred to the supplier and the products are delivered to the retailer.

Time $t=1$ : the retailer sells the products in the market at the certain market price per unit $(p)$. Herein, the market price is assumed to be outside of the negotiation scope between the supplier and the retailer and fixed (i.e. it is not a decision variable of any of the supply chain parties). As the demand is realized, the retailer firstly transfers the supplier her share of revenue and then repays the debt with imputed interest payment to the bank.

Schematically the flows which appear as a result of the revenue-sharing contract with bank financing application are presented (Figure 1). 


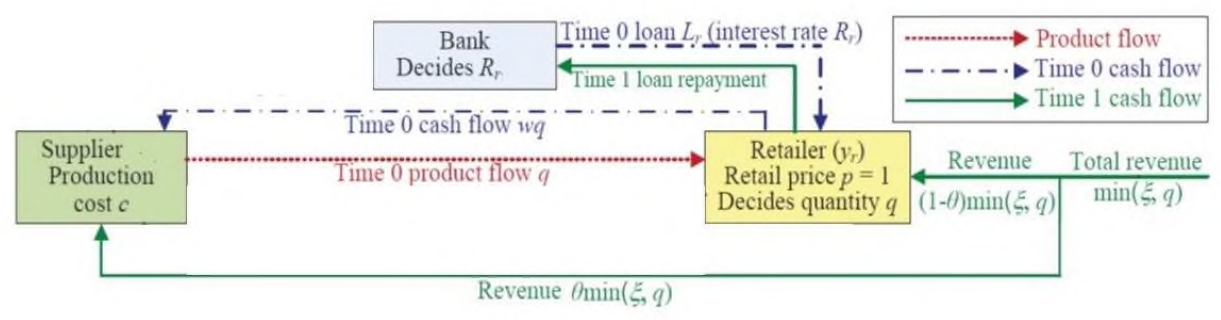

Fig. 1. The flows under a revenue-sharing contract with bank financing application. Source: authors own.

The following conditions are assumed within the model:

$$
\begin{gathered}
0<c_{R}<p, \\
0<\omega<p, \\
\varphi \in(0 ; 1), \\
r_{R}^{B} \in(0 ; 1) .
\end{gathered}
$$

Interaction within the framework of a revenue-sharing contract with bank financing for the retailer between the retailer and the supplier can be presented as the two-step, two-player game and looks as following: the supplier is a leader and chooses her strategy first, and the retailer is a follower. The supplier's strategy is to choose two parameters: $\omega, \varphi$ from the available set $\left(X_{S}\right)$; the retailer chooses only the volume of purchased products $(q)$ also from the available set $\left(X_{R}\right)$ :

$$
\begin{gathered}
X_{S}=\{(\varphi, \omega) \mid \varphi \in(0 ; 1) ; 0<\omega<p\} ; \\
X_{R}=\{q(\varphi, \omega) \mid q \geq 0\} .
\end{gathered}
$$

Thus, the revenue-sharing contract with bank financing for the retailer is defined with a combination of following three parameters: $(\varphi, \omega, q)$ and is defined the same as a traditional revenue-sharing contract (Cachon, 2003).

The expected profit for one transaction is considered as a payoff function both for the supplier $\left(\mathbb{E}\left[\pi_{S}\right]\right)$ and the retailer $\left(\mathbb{E}\left[\pi_{R}\right]\right)$ :

$$
\begin{aligned}
& \mathbb{E}\left[\pi_{S}\right]=\mathbb{E}\left[\pi_{S}\right](\varphi, \omega, q)=\mathbb{E}\left[\pi_{S}\right](\varphi, \omega(\varphi), q(\varphi, \omega(\varphi))), \\
& \mathbb{E}\left[\pi_{R}\right]=\mathbb{E}\left[\pi_{R}\right](\varphi, \omega, q)=\mathbb{E}\left[\pi_{R}\right](\varphi, \omega(\varphi), q(\varphi, \omega(\varphi))) .
\end{aligned}
$$

It is assumed that when choosing a strategy, the players act rationally, and aim to maximize their profits, while the case in which one player gets the entire profit is excluded.

For solving supply chain coordination problem, the definition of a coordinating revenue sharing contract is based on one proposed by Berezinets et al. (2019). Let $\mathbb{E}\left[\pi_{S C}\right](q)$ denote the supply chain profit expectation, and $q_{S C}^{*}$ is the local point for maximum point for this function: that is, $\mathbb{E}\left[\pi_{S c}\right]\left(q_{S C}^{*}\right)=\max _{q} \mathbb{E}\left[\pi_{S C}\right](q)$. Let define a coordinating revenue-sharing contract. 
Definition 1. A revenue-sharing contract $\left(\boldsymbol{\varphi}^{*}, \boldsymbol{\omega}^{*}, \boldsymbol{q}^{*}\right)$ will coordinate the supply chain if the following conditions are met:

(1) $\max _{q} \mathbb{E}\left[\pi_{R}\right](\varphi, \omega, q)=\mathbb{E}\left[\pi_{R}\right]\left(\varphi, \omega, q_{R}^{*}(\varphi, \omega)\right)$, for any $(\varphi, \omega) \in X_{S}$;

(2) there is a function $\omega^{*}(\varphi)$, for which the following is correct: $q_{R}^{*}\left(\varphi, \omega^{*}(\varphi)\right)=$ $q_{S C}^{*}=q^{*}$, for any $(\varphi, \omega(\varphi)) \in X_{S}$;

(3) $\max _{(\varphi) \in D\left(\omega^{*}, q^{*}\right)} \mathbb{E}\left[\pi_{S}\right]\left(\varphi, \omega^{*}(\varphi), q^{*}\right)=\mathbb{E}\left[\pi_{S}\right]\left(\varphi^{*}, \omega^{*}, q^{*}\right)$, where $\omega^{*}=\omega^{*}\left(\varphi^{*}\right)$, $D\left(\omega^{*}, q^{*}\right)=\left\{\varphi \mid\left(\varphi, \omega^{*}(\varphi)\right) \in X_{S}\right\}$.

Thus, the determination of the parameters of a coordinating contract consists of the following steps:

1) Determination of the optimal order volume for the retailer $\left(q_{R}^{*}\right)$;

2) Determination of the optimal order volume for the supply chain $\left(q_{S C}^{*}\right)$;

3) Determination of the wholesale price value $\omega^{*}$, for which the optimal order volume for the retailer coincides with the optimal order volume for the supply chain $\left(q_{R}^{*}=q_{S C}^{*}=q^{*}\right)$;

4) Determination of the parameter $\varphi$, for which the expected profit of the supplier $\left(\mathbb{E}\left[\pi_{S}\right]\right)$ is maximized for obtained $q^{*}$ and $\omega^{*}$.

The expressions for the supplier, retailer, and supply chain profits are as following:

$$
\begin{gathered}
\pi_{R}(\varphi, \omega, q)=(1-\varphi) p \tau-\left(\omega+c_{R}\right)\left(1+r_{R}^{B}\right) q+K_{R} r_{R}^{B} \\
\pi_{S}(\varphi, \omega, q)=\varphi p \tau+\left(\omega-c_{S}\right) q \\
\pi_{S C}(\omega, q)=p \tau-\left(c+\left(\omega+c_{R}\right) r_{R}^{B}\right) q+K_{R} r_{R}^{B} .
\end{gathered}
$$

Respectively, the expected profits of the parties and the supply chain are as following:

$$
\begin{gathered}
\mathbb{E}\left[\pi_{R}\right](\varphi, \omega, q)=(1-\varphi) p \mathbb{E}[\tau]-\left(\omega+c_{R}\right)\left(1+r_{R}^{B}\right) q+K_{R} r_{R}^{B}= \\
=(1-\varphi) p\left(q-\int_{0}^{q} F_{\xi}(x) d x\right)-\left(\omega+c_{R}\right)\left(1+r_{R}^{B}\right) q+K_{R} r_{R}^{B}, \\
\mathbb{E}\left[\pi_{S}\right](\varphi, \omega, q)=\varphi p \mathbb{E}[\tau]+\left(\omega-c_{S}\right) q=\varphi p\left(q-\int_{0}^{q} F_{\xi}(x) d x\right)+\left(\omega-c_{S}\right) q, \\
\mathbb{E}\left[\pi_{S C}\right](\omega, q)=p \mathbb{E}[\tau]-\left(c+\left(\omega+c_{R}\right) r_{R}^{B}\right) q+K_{R} r_{R}^{B}= \\
=p\left(q-\int_{0}^{q} F_{\xi}(x) d x\right)-\left(c+\left(\omega+c_{r}\right) r_{R}^{B}\right) q+K_{r} r_{R}^{B} .
\end{gathered}
$$

It is important to admit that as the retailer is assumed to be in need of shortterm financing, the following inequation is held: $\left(\omega+c_{R}\right) q-K_{R}>0$.

Determination of the optimal order volume for the retailer $\left(q_{R}^{*}\right)$

The retailer chooses order volume $q$ from the supplier being familiar with the supplier's offers on the values of $\varphi$ and $\omega$. According to the definition 1 of a coordinating contract, the retailer chooses the volume $q$ that will maximize his profit expectation $\mathbb{E}\left[\pi_{R}\right](\varphi, \omega, q)$. Thus, we need to find the stationary point of function 
$\mathbb{E}\left[\pi_{R}\right](\varphi, \omega, q)$, considering it as a function of single variable $q$. For that, calculation of the first derivative is done, and it is equaled to zero:

$$
\frac{\partial \mathbb{E}\left[\pi_{R}\right](\varphi, \omega, q)}{\partial q}=(1-\varphi) p\left(1-F_{\xi}(q)\right)-\left(\omega+c_{R}\right)\left(1+r_{R}^{B}\right)=0 .
$$

From the expression above:

$$
F_{\xi}(q)=\frac{(1-\varphi) p-\left(\omega+c_{R}\right)\left(1+r_{R}^{B}\right)}{(1-\varphi) p} .
$$

According to the assumption of $F_{\xi}(x)$ and, consequently, of $F_{\xi}(q)$ being strictly increasing, it has an inverse function. Thus, the stationary point $q_{R}^{0}$ of $\mathbb{E}\left[\pi_{R}\right](\varphi, \omega, q)$ can be found:

$$
q_{R}^{0}=F_{\xi}^{-1}\left(\frac{(1-\varphi) p-\left(\omega+c_{R}\right)\left(1+r_{R}^{B}\right)}{(1-\varphi) p}\right) .
$$

To examine whether the found stationary point is the local point for maximum point for function $\mathbb{E}\left[\pi_{R}\right](\varphi, \omega, q)$ the second derivative of this function is calculated. According to the stated previously conditions, $\varphi<1$ and density function $f_{\xi}(x)$ is positive, thus, the second derivative is always negative at the stationary point:

$$
\frac{\partial^{2} \mathbb{E}\left[\pi_{R}\right](\varphi, \omega, q)}{\partial q^{2}}=(1-\varphi) p\left(-f_{\xi}\left(q^{0}\right)\right)<0 .
$$

Therefore, the stationary point $q_{R}^{0}$ is the local point for maximum point $q_{R}^{*}$ for function $\mathbb{E}\left[\pi_{R}\right](\varphi, \omega, q)$ :

$$
q_{R}^{0}=q_{R}^{*}=F_{\xi}^{-1}\left(\frac{(1-\varphi) p-\left(\omega+c_{R}\right)\left(1+r_{R}^{B}\right)}{(1-\varphi) p}\right) .
$$

Determination of the optimal order volume for the supply chain $\left(q_{S C}^{*}\right)$

The next step of coordinating contract construction is to define the optimal wholesale price $\omega^{*}$, for which the following condition is met:

$$
q_{R}^{*}=q_{S C}^{*}
$$

where $q_{S C}^{*}$ is the local point for maximum point for the supply chain's expected profit $\mathbb{E}\left[\pi_{S C}\right](\omega, q)$.

The first derivative of function $\mathbb{E}\left[\pi_{S C}\right](\omega, q)$ and the necessary extreme condition of this function are as follows:

$$
\frac{\partial \mathbb{E}\left[\pi_{S C}\right](\omega, q)}{\partial q}=p\left(1-F_{\xi}(q)\right)-\left(c+\left(\omega+c_{R}\right) r_{R}^{B}\right)=0,
$$

and, consequently,

$$
F_{\xi}(q)=\frac{p-c-\left(\omega+c_{R}\right) r_{R}^{B}}{p} .
$$

The expression of the stationary point $q_{S C}^{0}$ is derived:

$$
q_{S C}^{0}=F_{\xi}^{-1}\left(\frac{p-c-\left(\omega+c_{R}\right) r_{R}^{B}}{p}\right) .
$$


The second derivative of function $\mathbb{E}\left[\pi_{S C}\right](\omega, q)$ is presented. Similarly to the retailer's case it can be shown that the stationary point $q_{S C}^{0}$ will be the local point for maximum point for function $\mathbb{E}\left[\pi_{S C}\right](\omega, q)$ :

$$
\begin{gathered}
\frac{\partial^{2} \mathbb{E}\left[\pi_{S C}\right](\omega, q)}{\partial q^{2}}=p\left(-f_{\xi}\left(q^{0}\right)\right)<0, \\
q_{S C}^{0}=q_{S C}^{*}=F_{\xi}^{-1}\left(\frac{p-c-\left(\omega+c_{R}\right) r_{R}^{B}}{p}\right) .
\end{gathered}
$$

Determination of the wholesale price value $\omega^{*}$

From the condition of $q_{R}^{*}=q_{S C}^{*}$, we have the following:

$$
F_{\xi}^{-1}\left(\frac{(1-\varphi) p-\left(\omega+c_{R}\right)\left(1+r_{R}^{B}\right)}{(1-\varphi) p}\right)=F_{\xi}^{-1}\left(\frac{p-c-\left(\omega+c_{R}\right) r_{R}^{B}}{p}\right) .
$$

According to the assumption of strictly increasing function $F_{\xi}(x)$, the following equality holds:

$$
\frac{(1-\varphi) p-\left(\omega+c_{R}\right)\left(1+r_{R}^{B}\right)}{(1-\varphi) p}=\frac{p-c-\left(\omega+c_{R}\right) r_{R}^{B}}{p} .
$$

From the previous equation, the function of $\omega^{*}$ is found which enables us to find the order volume of product $q^{*}=q_{R}^{*}=q_{S C}^{*}$, resulting in maximizing both the retailer's and the supply chain's profit expectation:

$$
\omega^{*}=c_{s}-c \varphi \frac{1+r_{R}^{B}}{1+\varphi r_{R}^{B}} .
$$

The existing conditions $\left(\omega<p, 0<r_{R}^{B}<1,0<\varphi<1\right)$ do not change the restrictions of $\varphi$, meaning that for all $\varphi$ from the available set we are able to continue construction of coordinating contract. Moreover, as can be seen, optimal wholesale price $\omega^{*}$ is less than a unit production $\operatorname{cost} c_{s}$. This discrepancy is covered with the share of the retailer's revenue transferred at the end of the selling season.

Determination of the parameter $\varphi$

Up to now the parameters $q^{*}$ and $\omega^{*}$ are found, which comply with the first two conditions of definition 1 of a coordinating contract, i.e. the properties of individual rationality for the retailer (maximization of retailer's expected profit) and collective rationality for the supply chain (maximization of supply chain expected profit) are fulfilled. The next step will be done to find such value for parameter $\varphi$, which provides the maximum of the supplier's expected profit. For this aim, the obtained values of parameters $q^{*}(7)$ and $\omega^{*}(9)$ are put into the expression for the supplier's profit expectation, and the first derivative of the function $\mathbb{E}\left[\pi_{S}\right]\left(\varphi, \omega^{*}, q^{*}\right)$, which under fixed values $\left(\omega^{*}, q^{*}\right)$ becomes the function of a single variable $\varphi$, is calculated.

The expression for function $\mathbb{E}\left[\pi_{s}\right]\left(\varphi, \omega^{*}, q^{*}\right)$ is as follows:

$$
\mathbb{E}\left[\pi_{s}\right]\left(\varphi, \omega^{*}, q^{*}\right)=\varphi p\left(q^{*}-\int_{0}^{q^{*}} F_{\xi}(x) d x\right)+\left(\omega^{*}-c_{s}\right) q^{*} .
$$

Putting the expressions for $q^{*}(7)$ and $\omega^{*}(9)$ into it, we get: 


$$
\begin{gathered}
\mathbb{E}\left[\pi_{s}\right]\left(\varphi, \omega^{*}, q^{*}\right)=\varphi\left[\left(p-c \frac{1+r_{R}^{B}}{1+\varphi r_{R}^{B}}\right) F_{\xi}^{-1}\left(1-\frac{c\left(1+r_{R}^{B}\right)}{p\left(1+\varphi r_{R}^{B}\right)}\right)-\right. \\
\left.p \int_{0}^{F_{\xi}^{-1}\left(1-\frac{c\left(1+r_{R}^{B}\right)}{p\left(1+\varphi r_{R}^{B}\right)}\right)} F_{\xi}(x) d x\right] .
\end{gathered}
$$

Here it is important to admit that as the expression $F_{\xi}^{-1}\left(1-\frac{c\left(1+r_{R}^{B}\right)}{p\left(1+\varphi r_{R}^{B}\right)}\right)$ stands for the retailer's optimal order quantity $q^{*}$ and any probability distribution function $F_{\xi}(x)$ can only take values from the interval $[0 ; 1]$, the following inequalities must be held:

$$
0 \leq 1-\frac{c\left(1+r_{R}^{B}\right)}{p\left(1+\varphi r_{R}^{B}\right)} \leq 1,
$$

which after the transformations give us the restrictions for supplier's revenue share $\varphi$ :

$$
\begin{gathered}
\varphi \geq \frac{c\left(1+r_{R}^{B}\right)-p}{p r_{R}^{B}}, \\
\varphi \geq-\frac{1}{r_{R}^{B}} .
\end{gathered}
$$

The second restriction is true for any value of the bank's interest rate. Thus, the restriction for the supplier's revenue share looks as follows:

$$
\varphi \geq \frac{c\left(1+r_{R}^{B}\right)-p}{p r_{R}^{B}} .
$$

For the stationary point obtaining the first derivative of the function $\mathbb{E}\left[\pi_{S}\right]\left(\varphi, \omega^{*}, q^{*}\right)$ is calculated and the necessary extreme condition of this function is presented:

$$
\begin{array}{r}
\frac{\partial \mathbb{E}\left[\pi_{s}\right]\left(\varphi, \omega^{*}, q^{*}\right)}{\partial \varphi}=F_{\xi}^{-1}\left(1-\frac{c\left(1+r_{R}^{B}\right)}{p\left(1+\varphi r_{R}^{B}\right)}\right)\left[p-\frac{c\left(1+r_{R}^{B}\right)}{\left(1+\varphi r_{R}^{B}\right)^{2}}\right]- \\
-p \int_{0}^{F_{\xi}^{-1}\left(1-\frac{c\left(1+r_{R}^{B}\right)}{p\left(1+\varphi r_{R}^{B}\right)}\right)} F_{\xi}(x) d x=0 .
\end{array}
$$

The second derivative of the function $\mathbb{E}\left[\pi_{S}\right]\left(\varphi, \omega^{*}, q^{*}\right)$ is presented:

$$
\begin{aligned}
\frac{\partial^{2} \mathbb{E}\left[\pi_{s}\right]\left(\varphi, \omega^{*}, q^{*}\right)}{\partial \varphi^{2}}=\frac{c \varphi r_{R}^{B}\left(1+r_{R}^{B}\right)}{\left(1+\varphi r_{R}^{B}\right)^{2}} & {\left[\frac{\partial F_{\xi}^{-1}\left(1-\frac{c\left(1+r_{R}^{B}\right)}{p\left(1+\varphi r_{R}^{B}\right)}\right)}{\partial \varphi}+\right.} \\
+ & \left.\frac{2}{1+\varphi r_{R}^{B}} F_{\xi}^{-1}\left(1-\frac{c\left(1+r_{R}^{B}\right)}{p\left(1+\varphi r_{R}^{B}\right)}\right)\right]
\end{aligned}
$$


In case of the second derivative being negative, the stationary point obtained will be the local point for maximum point for function $\mathbb{E}\left[\pi_{s}\right]\left(\varphi, \omega^{*}, q^{*}\right)$.

For further calculations, the information about certain demand distribution is needed.

Suppose that a random variable $\xi$ is a random variable distributed as uniformly on the interval $[0 ; \beta]$. In this case, the random variable distribution function of $\xi$ has the following form:

$$
F_{\xi}(x)= \begin{cases}0, & x \leq 0 \\ \frac{x}{\beta}, & 0<x \leq \beta \\ 1, & x>\beta\end{cases}
$$

Hence, $F_{\xi}(q)=\frac{q}{\beta}, q^{*}=F_{\xi}^{-1}\left(1-\frac{c\left(1+r_{R}^{B}\right)}{p\left(1+\varphi r_{R}^{B}\right)}\right)$, then

$$
q^{*}=\beta\left(1-\frac{c\left(1+r_{R}^{B}\right)}{p\left(1+\varphi r_{R}^{B}\right)}\right) .
$$

Subsequently:

$$
\begin{array}{r}
\int_{0}^{q} F_{\xi}(x) d x=\int_{0}^{F_{\xi}^{-1}\left(1-\frac{c\left(1+r_{R}^{B}\right)}{p\left(1+\varphi r_{R}^{B}\right)}\right)} F_{\xi}(x) d x=\int_{0}^{F_{\xi}^{-1}\left(1-\frac{c\left(1+r_{R}^{B}\right)}{p\left(1+\varphi r_{R} B\right)}\right)} \frac{x}{\beta} d x= \\
=\frac{\left(F_{\xi}^{-1}\left(1-\frac{c\left(1+r_{R}^{B}\right)}{p\left(1+\varphi r_{R}^{B}\right)}\right)\right)^{2}}{2 \beta}=\frac{\beta\left(1-\frac{c\left(1+r_{R}^{B}\right)}{p\left(1+\varphi r_{R}^{B}\right)}\right)^{2}}{2} .
\end{array}
$$

The necessary extreme condition of function $\mathbb{E}\left[\pi_{s}\right]\left(\varphi, \omega^{*}, q^{*}\right)(11)$ with the introduction of expressions of the distribution function is presented:

$$
\begin{aligned}
& \frac{\partial \mathbb{E}\left[\pi_{s}\right]\left(\varphi, \omega^{*}, q^{*}\right)}{\partial \varphi}=F_{\xi}^{-1}\left(1-\frac{c\left(1+r_{R}^{B}\right)}{p\left(1+\varphi r_{R}^{B}\right)}\right) {\left[\left(p-\frac{c\left(1+r_{R}^{B}\right)}{\left(1+\varphi r_{R}^{B}\right)^{2}}\right)-\right.} \\
&\left.-p \frac{F_{\xi}^{-1}\left(1-\frac{c\left(1+r_{R}^{B}\right)}{p\left(1+\varphi r_{R}^{B}\right)}\right)}{2 \beta}\right]=0 .
\end{aligned}
$$

The expression can have a zero value when one of the multipliers is equal to zero. But the first multiplier $F_{\xi}^{-1}\left(1-\frac{c\left(1+r_{R}^{B}\right)}{p\left(1+\varphi r_{R}^{B}\right)}\right)$ which represents the parameter $q^{*}$ should deviate from zero for the contract to be signed, thus, the second multiplier must be equal to zero:

$$
\left(p-\frac{c\left(1+r_{R}^{B}\right)}{\left(1+\varphi r_{R}^{B}\right)^{2}}\right)-p \frac{F_{\xi}^{-1}\left(1-\frac{c\left(1+r_{R}^{B}\right)}{p\left(1+\varphi r_{R}^{B}\right)}\right)}{2 \beta}=0 .
$$


Transformation done with this expression leads us to the quadratic equation which have the following roots:

$$
\begin{aligned}
& \varphi^{2} r_{R}^{B^{2}} p+\varphi r_{R}^{B}\left(2 p+c\left(1+r_{R}^{B}\right)\right)+\left(p-c\left(1+r_{R}^{B}\right)\right)=0, \\
& \varphi_{1}=\frac{-b+\sqrt{D}}{2 a}=\frac{-\left(2 p+c\left(1+r_{R}^{B}\right)\right)+\sqrt{c\left(1+r_{R}^{B}\right)\left(8 p+c\left(1+r_{R}^{B}\right)\right)}}{2 p r_{R}{ }^{B}} \text {, } \\
& \varphi_{2}=\frac{-b-\sqrt{D}}{2 a}=\frac{-\left(2 p+c\left(1+r_{R}^{B}\right)\right)-\sqrt{c\left(1+r_{R}^{B}\right)\left(8 p+c\left(1+r_{R}^{B}\right)\right)}}{2 p r_{R}{ }^{B}} .
\end{aligned}
$$

It is obvious that the second root is negative and outside the available set. Let us check whether the first root belongs to the available set of supplier's strategies.

$$
\begin{gathered}
\varphi_{1}>0 \Rightarrow \varphi_{1}=\frac{-\left(2 p+c\left(1+r_{R}^{B}\right)\right)+\sqrt{c\left(1+r_{R}^{B}\right)\left(8 p+c\left(1+r_{R}^{B}\right)\right)}}{2 p r_{R}^{B}}>0 ; \\
r_{R}^{B}>\frac{p}{c}-1 . \\
\varphi_{1}<1 \Rightarrow \varphi_{1}=\frac{-\left(2 p+c\left(1+r_{R}^{B}\right)\right)+\sqrt{c\left(1+r_{R}^{B}\right)\left(8 p+c\left(1+r_{R}^{B}\right)\right)}}{2 p r_{R}^{B}}<1 ; \\
r_{R}^{B}>\frac{c-p}{c+p} .
\end{gathered}
$$

For the obtained $\varphi$ to belong to available set of supplier's strategies, the presented interactions between the market price, unit cost of supply chain and bank's interest rate must be fulfilled. As from (15) $\frac{c-p}{c+p}<0$, the only restriction left is (14): $r_{R}^{B}>\frac{p}{c}-1$.

There is also another restriction posted on the supplier's revenue share $\varphi$ earlier (11) due to non-negativity of retailer's optimal order quantity $q^{*}$ :

$$
\begin{gathered}
\varphi_{1} \geq \frac{c\left(1+r_{R}^{B}\right)-p}{p r_{R}^{B}} \Rightarrow \\
\varphi_{1}=\frac{-\left(2 p+c\left(1+r_{R}^{B}\right)\right)+\sqrt{c\left(1+r_{R}^{B}\right)\left(8 p+c\left(1+r_{R}^{B}\right)\right)}}{2 p r_{R}^{B}} \geq \frac{c\left(1+r_{R}^{B}\right)-p}{p r_{R}^{B}} \\
r_{R}^{B} \leq \frac{p}{c}-1 .
\end{gathered}
$$

It is obvious that the restriction (16), which stands for the retailer's optimal order quantity $q^{*}$ to be non-negative, contradicts the restriction of positivity of the supplier's revenue share $\varphi$ (14) meaning that there are no such $\varphi$ values which are both maximizing the supplier's profit and belong to the available set of supplier's and retailer's strategies and this fact is proved empirically on the simulated data. Consequently, the inspected revenue-sharing contract with bank financing of the retailer is not a coordinating one according to the definition 1 of a coordinating contract as the property of the individual rationality for the supplier (maximization of supplier's expected profit) is not fulfilled.

Even though the inspected revenue-sharing contract with bank financing cannot maximize the supplier's expected profit and does not unconditionally coordinate the 
supply chain, it is possible that under this contract the supplier's profit expectations are still greater than without it. If it is achieved, then the contract is a conditionally coordinating contract.

Definition 2. If there is a revenue-sharing contract $\left(\varphi^{0}, \omega^{0}, q^{*}\right)$ that complies with conditions 1 and 2 of definition 1 , and the following inequation is true,

$$
\mathbb{E}\left[\pi_{S}\right]\left(\varphi^{0}, \omega^{0}, q^{*}\right)>\mathbb{E}\left[\pi_{S}\right]\left(\omega^{0}, q^{*}\right),
$$

where $\omega^{0}=\omega^{*}\left(\varphi^{0}\right)$, we can call it a conditionally coordinating contract.

Precisely speaking, for a conditionally coordinating revenue-sharing contract $\left(\varphi^{0}, \omega^{0}, q^{*}\right)$ the supplier's expected profit will be greater than in the case of a wholesale-price contract with bank financing parameters $\left(\omega^{0}, q^{*}\right)$ which are achieved by selection of a parameter $\varphi$, which is denoted by $\varphi^{0}$ in definition 2 and this set of parameters is denoted as $D^{0}\left(\omega^{*}, q^{*}\right)$.

For the ease of analysis, the expressions for the expected profits of the supplier, retailer and the supply chain are presented in the Table 3 .

Table 3. Expressions for expected profits of the supply chain and its parties for a product with demand distributed as uniformly

\begin{tabular}{|c|c|c|}
\hline Supply chain & Supplier & Retailer \\
\hline Revenue-sharing contract with bank financing \\
\hline $\mathbb{E}\left[\pi_{S C}\right]^{r s h}$ & $\mathbb{E}\left[\pi_{S}\right]^{r s h}$ & $\mathbb{E}\left[\pi_{R}\right]^{r s h}$ \\
\hline$p\left(q-\frac{q^{2}}{2 \beta}\right)-$ & $\varphi p\left(q-\frac{q^{2}}{2 \beta}\right)+$ & $(1-\varphi) p\left(q-\frac{q^{2}}{2 \beta}\right)-$ \\
$-\left(c+\left(\omega+c_{r}\right) r_{R}{ }^{B}\right) q+K_{r} r_{R}{ }^{B}$ & $\begin{array}{c}\text { W } \\
+\left(\omega-c_{S}\right) q\end{array}$ & $-\left(\omega+c_{R}\right)\left(1+r_{R}{ }^{B}\right) q+K_{R} r_{R}{ }^{B}$, \\
\hline \multicolumn{2}{|c|}{ Wholesale-price contract with bank financing } \\
\hline $\mathbb{E}\left[\pi_{S C}\right]^{w}$ & $\mathbb{E}\left[\pi_{S}\right]^{w}$ & $\mathbb{E}\left[\pi_{R}\right]^{w}$ \\
\hline$p\left(q-\frac{q^{2}}{2 \beta}\right)-$ & $\left(\omega-c_{S}\right) q$ & $p\left(q-\frac{q^{2}}{2 \beta}\right)-$ \\
$-\left(c+\left(\omega+c_{r}\right) r_{R}{ }^{B}\right) q+K_{r} r_{R}{ }^{B}$ & & $-\left(\omega+c_{R}\right)\left(1+r_{R}{ }^{B}\right) q+K_{R} r_{R}{ }^{B}$, \\
\hline
\end{tabular}

As can be seen from the table, the expected profit of the supplier can be written in the following way, from which it is obvious that the supplier's expected profit under the revenue-sharing contract with bank financing will be greater if the second term in a sum is positive, what is actually the case for any value of parameter $\varphi$ from the available set:

$$
\mathbb{E}\left[\pi_{S}\right]^{r s h}\left(\varphi, \omega^{*}, q^{*}\right)=\mathbb{E}\left[\pi_{S}\right]^{w}\left(\omega^{*}, q^{*}\right)+\varphi p\left(q^{*}-\frac{q^{* 2}}{2 \beta}\right) .
$$

Nevertheless, it is important to stress the following issue. As it is stated above, the optimal wholesale price $\omega^{*}$ under the revenue-sharing contract with bank financing is lower than the production $\operatorname{costs} c_{S}$, what is inapplicable for the wholesale-price contract as it leads to the losses of the supplier for any retailer's order quantity $q$ and such contract will not be signed. On the other side, the optimal wholesale price 
in case of the wholesale-price contract is equal to the production costs, and its application instead of the optimal wholesale price of the revenue-sharing contract also leads to the dominance by the revenue-sharing contract as in this case the expected profit of the supplier deviates from zero. Based on comparison of supply chain's parties expected profits we can say that the supplier is able to redistribute the supply chain's profit through the parameter $\varphi$ choice for her benefit.

Thus, for any $\varphi^{0}$ from the set $D^{0}\left(\omega^{*}, q^{*}\right)=\left\{\varphi^{0}: 0<\varphi^{0}<1\right\}$ the inspected revenue-sharing contract with bank financing $\left(\varphi^{0}, \omega^{*}\left(\varphi^{0}\right), q^{*}\right)$ is a conditionally coordinating contract according to the definition 2 .

\section{Supply Chain Coordination Based on Modified Revenue Sharing Contract with Trade Credit Financing under the Assumption that Demand is Distributed as Uniformly}

The assumptions made (Table 1) and notations used (Table 2) for the revenuesharing contract with bank financing modelling are still relevant for the modified revenue-sharing contract with trade credit financing.

Time $t=0$ : based on the decision of retailer to use a trade credit financing, at the first step the supplier offers the retailer the following contract parameters: the wholesale price per unit $(\omega)$, the interest rate $\left(r_{R}{ }^{S}\right)$ and a share of the retailer's revenue $(\varphi)$ which the retailer must transfer to the supplier at the end of the sales season. Considering the suppliers' conditions offered, the retailer decides on the quantity of goods $(q)$ he should order to maximize his profit based on the market demand information. Signing the contract means that the retailer postpones the wholesale price payment $(\omega q)$ and the supplier bears the retailer's costs for realization $\left(c_{R} q\right)$ for the price $r_{R}{ }^{S}$, but at this time point the partial transfer of the cash available $\left(K_{R}\right)$, is possible (this is equivalent to borrowing from the supplier). After the contract is signed the products are delivered to the retailer.

Time $t=1$ : the retailer sells the products in the market at the certain market price per unit $(p)$. Herein, the market price is also assumed to be outside of the negotiation scope between the supplier and the retailer and fixed (i.e. it is not a decision variable of any of the supply chain parties). As the demand is realized, the retailer transfers the supplier her share of revenue and repays the debt with imputed interest payment.

Schematically the flows which appear as a result of the modified revenue-sharing contract with trade credit financing application are presented (Figure 2).

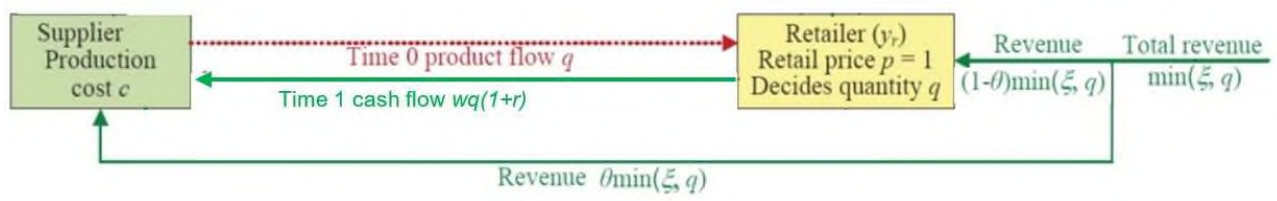

Fig. 2. The flows under a modified revenue-sharing contract with trade credit financing application. Source: authors own.

The following conditions are assumed within the model: 


$$
\begin{gathered}
0<c_{R}<p, \\
0<\omega<p, \\
\varphi \in(0 ; 1), \\
r_{R}^{S} \in(0 ; 1) .
\end{gathered}
$$

Interaction within the framework of a modified revenue-sharing contract with trade credit financing for the retailer between the retailer and the supplier can be presented as the two-step, two-player game and looks as following: the supplier is a leader and chooses her strategy first, and the retailer is a follower. The supplier's strategy is to choose three parameters: $\omega, \varphi, r_{R}{ }^{S}$ from the available set $\left(X_{S}\right)$; the retailer chooses only the volume of purchased products $(q)$ also from the available set $\left(X_{R}\right)$ :

$$
\begin{gathered}
X_{S}=\left\{\left(\varphi, \omega, r_{R}{ }^{S}\right) \mid \varphi \in(0 ; 1) ; 0<\omega<p, r_{R}{ }^{S} \in(0 ; 1)\right\} ; \\
X_{R}=\{q(\varphi, \omega) \mid q \geq 0\} .
\end{gathered}
$$

Thus, the modified revenue-sharing contract with trade credit financing of the retailer is defined with a combination of following four parameters: $\left(\varphi, \omega, q, r_{R}{ }^{S}\right)$. Its definition deviates from the traditional revenue-sharing contract (Cachon, 2003) by inclusion of parameter

$r_{R}{ }^{S}$.

The expected profit for one transaction is considered as a payoff function both for the supplier $\left(\mathbb{E}\left[\pi_{S}\right]\right)$ and the retailer $\left(\mathbb{E}\left[\pi_{R}\right]\right)$ :

$$
\begin{gathered}
\mathbb{E}\left[\pi_{S}\right]=\mathbb{E}\left[\pi_{S}\right]\left(\varphi, \omega, r_{R}{ }^{S}, q\right)=\mathbb{E}\left[\pi_{S}\right]\left(\varphi, \omega\left(\varphi, r_{R}{ }^{S}\right), r_{R}{ }^{S}, q\left(\varphi, \omega(\varphi), r_{R}{ }^{S}\right)\right), \\
\mathbb{E}\left[\pi_{R}\right]=\mathbb{E}\left[\pi_{R}\right]\left(\varphi, \omega, r_{R}{ }^{S}, q\right)=\mathbb{E}\left[\pi_{R}\right]\left(\varphi, \omega(\varphi), r_{R}{ }^{S}, q\left(\varphi, \omega(\varphi), r_{R}{ }^{S}\right)\right) .
\end{gathered}
$$

It is assumed that when choosing a strategy, the players act rationally, and aim to maximize their profits, while the case in which one player gets the entire profit is excluded.

For solving supply chain coordination problem, the definition of a coordinating modified revenue sharing contract is also based on the one proposed by Berezinets et al. (2019). Let $\mathbb{E}\left[\pi_{S C}\right](q)$ denote the supply chain profit expectation, and $q_{S C}^{*}$ is the local point for maximum point for this function: that is, $\mathbb{E}\left[\pi_{S c}\right]\left(q_{S C}^{*}\right)=$ $\max _{q} \mathbb{E}\left[\pi_{S C}\right](q)$. Let us define a coordinating modified revenue-sharing contract.

Definition 3. A modified revenue-sharing contract $\left(\varphi^{*}, \omega^{*}, \boldsymbol{r}_{R} S^{*}, \boldsymbol{q}^{*}\right)$ will coordinate the supply chain if the following conditions are met:

(1) $\max _{q} \mathbb{E}\left[\pi_{R}\right]\left(\varphi, r_{R}{ }^{S}, \omega, q\right)=\mathbb{E}\left[\pi_{R}\right]\left(\varphi, r_{R}{ }^{S}, \omega, q_{R}^{*}\left(\varphi, r_{R}{ }^{S}, \omega\right)\right)$, for any $\left(\varphi, r_{R}{ }^{S}, \omega\right) \in X_{S}$

(2) there is a function $\omega^{*}\left(\varphi, r_{R}^{S}\right)$, for which the following is correct: $q_{R}^{*}\left(\varphi, r_{R}{ }^{S}, \omega^{*}\left(\varphi, r_{R}^{S}\right)\right)=q_{S C}^{*}=q^{*}$, for any $\left(\varphi, r_{R}{ }^{S}, \omega\left(\varphi, r_{R}{ }^{S}\right)\right) \in X_{S} ;$ 
Coordinating Contracts as an Instrument of Supply Chain Profit Maximization 77

$$
\begin{aligned}
& \max _{\left(\varphi, r_{R} S\right) \in D\left(\omega^{*}, q^{*}\right)} \mathbb{E}\left[\pi_{S}\right]\left(\varphi, r_{R}{ }^{S}, \omega^{*}\left(\varphi, r_{R}{ }^{S}\right), q^{*}\right)=\mathbb{E}\left[\pi_{S}\right]\left(\varphi^{*}, r_{R}{ }^{S^{*}}, \omega^{*}, q^{*}\right), \\
& \text { where } \omega^{*}=\omega^{*}\left(\varphi^{*}, r_{R} S^{*}\right), D\left(\omega^{*}, q^{*}\right)=\left\{\left(\varphi, r_{R}{ }^{S}\right) \mid\left(\varphi, r_{R}{ }^{S}, \omega^{*}\left(\varphi, r_{R}{ }^{S}\right)\right) \in X_{S}\right\} .
\end{aligned}
$$

Thus, the determination of the parameters of a coordinating contract consists of the following steps:

1) Determination of the optimal order volume for the retailer $\left(q_{R}^{*}\right)$;

2) Determination of the optimal order volume for the supply chain $\left(q_{S C}^{*}\right)$;

3) Determination of the wholesale price value $\omega^{*}$, for which the optimal order volume for the retailer coincides with the optimal order volume for the supply chain $\left(q_{R}^{*}=q_{S C}^{*}=q^{*}\right)$;

4) Determination of the parameters $\varphi$ and $r_{R}{ }^{S}$, for which the expected profit of the supplier $\left(\mathbb{E}\left[\pi_{S}\right]\right)$ is maximized for obtained $q^{*}$ and $\omega^{*}$.

The expressions for the supplier, retailer, and supply chain profits are as following:

$$
\begin{gathered}
\pi_{R}\left(\varphi, r_{R}{ }^{S}, \omega, q\right)=(1-\varphi) p \tau-\left(\omega+c_{R}\right)\left(1+r_{R}{ }^{S}\right) q+K_{R} r_{R}{ }^{S}, \\
\pi_{S}\left(\varphi, r_{R}{ }^{S}, \omega, q\right)=\varphi p \tau+\left(\left(\omega+c_{R}\right) r_{R}{ }^{S}+\left(\omega-c_{s}\right)\right) q-K_{R} r_{R}{ }^{S}, \\
\pi_{S C}(q)=p \tau-c q .
\end{gathered}
$$

Respectively, the expected profits of the parties and the supply chain are as following:

$$
\begin{gathered}
\mathbb{E}\left[\pi_{R}\right]\left(\varphi, r_{R}{ }^{S}, \omega, q\right)=(1-\varphi) p \mathbb{E}[\tau]-\left(\omega+c_{R}\right)\left(1+r_{R}{ }^{S}\right) q+K_{R} r_{R}{ }^{S}= \\
=(1-\varphi) p\left(q-\int_{0}^{q} F_{\xi}(x) d x\right)-\left(\omega+c_{R}\right)\left(1+r_{R}{ }^{S}\right) q+K_{R} r_{R}{ }^{S}, \\
\mathbb{E}\left[\pi_{S}\right]\left(\varphi, r_{R}{ }^{S}, \omega, q\right)=\varphi p \mathbb{E}[\tau]+\left(\left(\omega+c_{R}\right) r_{R}{ }^{S}+\left(\omega-c_{s}\right)\right) q-K_{R} r_{R}{ }^{S}= \\
=\varphi p\left(q-\int_{0}^{q} F_{\xi}(x) d x\right)+\left(\left(\omega+c_{R}\right) r_{R}{ }^{S}+\left(\omega-c_{s}\right)\right) q-K_{R} r_{R}{ }^{S}, \\
\mathbb{E}\left[\pi_{S C}\right](q)=p \mathbb{E}[\tau]-c q=p\left(q-\int_{0}^{q} F_{\xi}(x) d x\right)-c q .
\end{gathered}
$$

As the retailer is assumed to be in need of short-term financing, the following inequation is held: $\left(\omega+c_{R}\right) q-K_{R}>0$.

Determination of the optimal order volume for the retailer $\left(q_{R}^{*}\right)$

The retailer chooses order volume $q$ from the supplier being familiar with the supplier's offers on the values of $\varphi, r_{R}{ }^{S}$ and $\omega$. According to the definition 3 of a coordinating contract, the retailer chooses the volume $q$ that will maximize his profit expectation $\mathbb{E}\left[\pi_{R}\right]\left(\varphi, r_{R}{ }^{S}, \omega, q\right)$. Thus, we need to find the stationary point of function $\mathbb{E}\left[\pi_{R}\right]\left(\varphi, r_{R} S, \omega, q\right)$, considering it as a function of single variable $q$. For that, calculation of the first derivative is done, and it is equaled to zero:

$$
\frac{\partial \mathbb{E}\left[\pi_{R}\right]\left(\varphi, r_{R}{ }^{S}, \omega, q\right)}{\partial q}=(1-\varphi) p\left(1-F_{\xi}(q)\right)-\left(\omega+c_{R}\right)\left(1+r_{R}{ }^{S}\right)=0 .
$$


From the expression above:

$$
F_{\xi}(q)=\frac{(1-\varphi) p-\left(\omega+c_{R}\right)\left(1+r_{R}^{S}\right)}{(1-\varphi) p} .
$$

According to the assumption of $F_{\xi}(x)$ and, consequently, of $F_{\xi}(q)$ being strictly increasing, it has an inverse function. Thus, the stationary point $q_{R}^{0}$ of $\mathbb{E}\left[\pi_{R}\right]\left(\varphi, r_{R}{ }^{S}, \omega\right.$, q) can be found:

$$
q_{R}^{0}=F_{\xi}^{-1}\left(\frac{(1-\varphi) p-\left(\omega+c_{R}\right)\left(1+r_{R}{ }^{S}\right)}{(1-\varphi) p}\right) .
$$

To examine whether the found stationary point is the local point for maximum point for function $\mathbb{E}\left[\pi_{R}\right]\left(\varphi, r_{R}{ }^{S}, \omega, q\right)$ the second derivative of this function is calculated. According to the stated previously conditions, $\varphi<1$ and density function $f_{\xi}(x)$ is positive, thus, the second derivative is always negative at the stationary point:

$$
\frac{\partial^{2} \mathbb{E}\left[\pi_{R}\right]\left(\varphi, r_{R}{ }^{S}, \omega, q\right)}{\partial q^{2}}=(1-\varphi) p\left(-f_{\xi}\left(q^{0}\right)\right)<0 .
$$

Therefore, the stationary point $q_{R}^{0}$ is the local point for maximum point $q_{R}^{*}$ for function $\mathbb{E}\left[\pi_{R}\right]\left(\varphi, r_{R}{ }^{S}, \omega, q\right)$ :

$$
q_{R}^{0}=q_{R}^{*}=F_{\xi}^{-1}\left(\frac{(1-\varphi) p-\left(\omega+c_{R}\right)\left(1+r_{R}{ }^{S}\right)}{(1-\varphi) p}\right) .
$$

Determination of the optimal order volume for the supply chain $\left(q_{S C}^{*}\right)$

The next step of coordinating contract construction is to define the optimal wholesale price $\omega^{*}$, for which the following condition is met:

$$
q_{R}^{*}=q_{S C}^{*},
$$

where $q_{S C}^{*}$ is the local point for maximum point for the supply chain's expected profit $\mathbb{E}\left[\pi_{S C}\right](q)$.

The first derivative of function $\mathbb{E}\left[\pi_{S C}\right](q)$ and the necessary extreme condition of this function are as follows:

$$
\frac{\partial \mathbb{E}\left[\pi_{S C}\right](q)}{\partial q}=p\left(1-F_{\xi}(q)\right)-c=0,
$$

and, consequently,

$$
F_{\xi}(q)=\frac{p-c}{p} .
$$

The expression of the stationary point $q_{S C}^{0}$ is derived:

$$
q_{S C}^{0}=F_{\xi}^{-1}\left(\frac{p-c}{p}\right) \text {. }
$$

The second derivative of function $\mathbb{E}\left[\pi_{S C}\right](q)$ is presented. Similarly to the retailer's case it can be shown that the stationary point $q_{S C}^{0}$ will be the local point for maximum point for function $\mathbb{E}\left[\pi_{S C}\right](q)$ :

$$
\frac{\partial^{2} \mathbb{E}\left[\pi_{S C}\right](q)}{\partial q^{2}}=p\left(-f_{\xi}\left(q^{0}\right)\right)<0,
$$




$$
q_{S C}^{0}=q_{S C}^{*}=F_{\xi}^{-1}\left(\frac{p-c}{p}\right) .
$$

Determination of the wholesale price value $\omega^{*}$

From the condition of $q_{R}^{*}=q_{S C}^{*}$, we have the following:

$$
F_{\xi}^{-1}\left(\frac{(1-\varphi) p-\left(\omega+c_{R}\right)\left(1+r_{R}^{S}\right)}{(1-\varphi) p}\right)=F_{\xi}^{-1}\left(\frac{p-c}{p}\right) .
$$

According to the assumption of strictly increasing function $F_{\xi}(x)$, the following equality holds:

$$
\frac{(1-\varphi) p-\left(\omega+c_{R}\right)\left(1+r_{R}{ }^{S}\right)}{(1-\varphi) p}=\frac{p-c}{p} .
$$

From the previous equation, the function of $\omega^{*}$ is found which enables us to find the order volume of product $q^{*}=q_{R}^{*}=q_{S C}^{*}$, resulting in maximizing both the retailer's and the supply chain's profit expectation:

$$
\omega^{*}=c_{s}-c \frac{\varphi+r_{R} S}{1+r_{R} S} .
$$

The existing conditions $\left(\omega<p, 0<r_{R}{ }^{S}<1,0<\varphi<1\right.$ ) do not change the restrictions of $\varphi$ and $r_{R}{ }^{S}$, meaning that for all $\varphi$ and for all $r_{R}{ }^{S}$ from the available set we are able to continue coordination construction. Moreover, as can be seen, optimal wholesale price $\omega^{*}$ is also less than a unit production $\operatorname{cost} c_{s}$. This discrepancy is covered with the share of the retailer's revenue transferred at the end of the selling season.

Determination of the parameters $\varphi$ and $r_{R}{ }^{S}$

Up to now the parameters $q^{*}(24)$ and $\omega^{*}(26)$ are found, which comply with the first two conditions of definition 3 of a coordinating contract, i.e. the properties of individual rationality for the retailer (maximization of retailer's expected profit) and collective rationality for the supply chain (maximization of supply chain expected profit) are fulfilled. The next step will be done to find such values for parameters $\varphi$ and $r_{R}{ }^{S}$, which provide the maximum of the supplier's expected profit. For this aim, the obtained values of parameters $q^{*}$ and $\omega^{*}$ are put into the expression for the supplier's profit expectation, and the first derivative of the function $\mathbb{E}\left[\pi_{S}\right]\left(\varphi, r_{R}{ }^{S}, \omega^{*}, q^{*}\right)$, which under fixed values $\left(\omega^{*}, q^{*}\right)$ becomes the function of a two variables: $\varphi$ and $r_{R}{ }^{S}$, is calculated.

The expression for function $\mathbb{E}\left[\pi_{s}\right]\left(\varphi, r_{R}{ }^{S}, \omega^{*}, q^{*}\right)$ is as follows:

$$
\begin{aligned}
\mathbb{E}\left[\pi_{s}\right]\left(\varphi, r_{R}{ }^{S}, \omega^{*}, q^{*}\right)=\varphi p\left(q^{*}-\int_{0}^{q^{*}} F_{\xi}(x) d x\right)+ & \left(\left(\omega^{*}+c_{R}\right) r_{R}{ }^{S}+\right. \\
& \left.+\left(\omega^{*}-c_{s}\right)\right) q^{*}-K_{R} r_{R}{ }^{S} .
\end{aligned}
$$

Putting the expressions for $q^{*}(24)$ and $\omega^{*}(26)$ into it, we get:

$$
\mathbb{E}\left[\pi_{s}\right]\left(\varphi, r_{R}{ }^{S}, \omega^{*}, q^{*}\right)=\varphi\left[(p-c) F_{\xi}^{-1}\left(\frac{p-c}{p}\right)-p \int_{0}^{F_{\xi}^{-1}\left(\frac{p-c}{p}\right)} F_{\xi}(x) d x\right]-
$$


For the stationary point $M_{0}\left(\varphi, r_{R}{ }^{S}\right)$ obtaining the first partial derivatives of the function $\mathbb{E}\left[\pi_{S}\right]\left(\varphi, r_{R}{ }^{S}, \omega^{*}, q^{*}\right)$ are calculated:

$$
\left\{\begin{array}{l}
\frac{\partial \mathbb{E}\left[\pi_{s}\right]\left(\varphi, r_{R}{ }^{S}, \omega^{*}, q^{*}\right)}{\partial \varphi}=(p-c) F_{\xi}^{-1}\left(\frac{p-c}{p}\right)-p \int_{0}^{F_{\xi}^{-1}\left(\frac{p-c}{p}\right)} F_{\xi}(x) d x \neq 0 \\
\frac{\partial \mathbb{E}\left[\pi_{s}\right]\left(\varphi, r_{R}{ }^{S}, \omega^{*}, q^{*}\right)}{\partial r_{R} S}=-K_{R} \neq 0 .
\end{array}\right.
$$

The necessary extreme condition of the function is not fulfilled, consequently, we can conclude that the maximum of function $\mathbb{E}\left[\pi_{S}\right]\left(\varphi, r_{R}{ }^{S}, \omega^{*}, q^{*}\right)$ in the set $D\left(\omega^{*}, q^{*}\right)$ does not exist. It means that it is not possible to find a combination of parameters $\left(\varphi^{*}, r_{R} S^{*}, \omega^{*}, q^{*}\right)$ that complies with all conditions of coordinating contract definition 3 (the property of the individual rationality for the supplier (maximization of supplier's expected profit) is not fulfilled), so the modified revenue-sharing contract does not coordinate the supply chain.

Even though, the modified revenue-sharing contract cannot maximize the supplier's expected profit and does not unconditionally coordinate the supply chain, it is possible that under this contract the supplier's profit expectations are still greater than without it. If it is achieved, then the contract is a conditionally coordinating contract.

Definition 4. If there is a modified revenue-sharing contract with trade credit financing $\left(\boldsymbol{\varphi}^{\mathbf{0}}, \boldsymbol{r}_{\boldsymbol{R}} \boldsymbol{S}^{\mathbf{0}}, \boldsymbol{\omega}^{\mathbf{0}}, \boldsymbol{q}^{*}\right)$ that complies with conditions 1 and 2 of definition 3 , and the following inequation is true,

$$
\mathbb{E}\left[\pi_{S}\right]\left(\varphi^{0}, r_{R} S^{0}, \omega^{0}, q^{*}\right)>\mathbb{E}\left[\pi_{S}\right]\left(r_{R} S^{0}, \omega^{0}, q^{*}\right),
$$

where $\omega^{0}=\omega^{*}\left(\varphi^{0}, r_{R} S^{0}\right)$, we can call it a conditionally coordinating contract.

Thus, for a conditionally coordinating modified revenue-sharing contract $\left(\varphi^{0}, r_{R} S^{0}, \omega^{0}, q^{*}\right)$ the supplier's expected profit will be greater than in the case of a modified wholesale-price contract with trade credit financing with parameters $\left(r_{R} S^{0}, \omega^{0}, q^{*}\right)$ which are achieved by selection of parameters $\varphi$ and $r_{R}{ }^{S}$, which are denoted by $\left(\varphi^{0}, r_{R} S^{0}\right)$ in definition 4 and this set of parameters is denoted by $D^{0}\left(\omega^{*}, q^{*}\right)$.

As here we test the modified revenue-sharing contract against the modified wholesale-price contract, i.e. we are interested in the impact of the presence of parameter $\varphi$ on the expected profit of the supplier under the modified revenuesharing contract, we assume that the parameter $r_{R} S^{0}$ is chosen the same for both contracts $\left(r_{R} S^{0^{m r s h}}=r_{R} S^{0^{m w}}=r_{R} S^{0}\right)$.

For the ease of analysis, the expressions for the expected profits of the supplier, retailer and the supply chain are presented in the Table 4.

The same as in the case of the revenue-sharing contract with bank financing, the expected profit of the supplier can be written in the following way, from which it is obvious that the supplier's expected profit under the modified revenue-sharing contract with trade credit financing will be greater if the second term in a sum is positive, what is actually the case for any values of parameters $\varphi$ and $r_{R}{ }^{S}$ from the available set: 
Table 4. Expressions for expected profits of the supply chain and its parties for a product with demand distributed as uniformly

\begin{tabular}{|c|c|c|}
\hline Supply chain & Supplier & Retailer \\
\hline \multicolumn{3}{|c|}{ Modified revenue-sharing contract with trade credit financing } \\
\hline $\mathbb{E}\left[\pi_{S C}\right]^{m r s h}$ & $\mathbb{E}\left[\pi_{S}\right]^{m r s h}$ & $\mathbb{E}\left[\pi_{R}\right]^{m r s h}$ \\
\hline$p\left(q-\frac{q^{2}}{2 \beta}\right)-c q$ & $\begin{array}{c}\varphi p\left(q-\frac{q^{2}}{2 \beta}\right)+ \\
+\left(\omega+c_{R}\right) q r_{R}{ }^{S}+ \\
+\left(\omega-c_{s}\right) q-K_{R} r_{R}^{S}\end{array}$ & $\begin{array}{c}(1-\varphi) p\left(q-\frac{q^{2}}{2 \beta}\right)- \\
-\left(\omega+c_{R}\right)\left(1+r_{R}^{S}\right) q+K_{R} r_{R}^{S}\end{array}$ \\
\hline \multicolumn{3}{|c|}{ Modified wholesale-price contract with trade credit financing } \\
\hline $\mathbb{E}\left[\pi_{S C}\right]^{m w}$ & $\mathbb{E}\left[\pi_{S}\right]^{m w}$ & $\mathbb{E}\left[\pi_{R}\right]^{m w}$ \\
\hline$p\left(q-\frac{q^{2}}{2 \beta}\right)-c q$ & $\begin{array}{c}\left(\omega+c_{R}\right) q r_{R}^{S}+ \\
+\left(\omega-c_{s}\right) q-K_{R} r_{R}^{S}\end{array}$ & $\begin{array}{c}p\left(q-\frac{q^{2}}{2 \beta}\right)- \\
-\left(\omega+c_{R}\right)\left(1+r_{R}{ }^{S}\right) q+K_{R} r_{R}{ }^{S}\end{array}$ \\
\hline
\end{tabular}

$$
\mathbb{E}\left[\pi_{S}\right]^{m r s h}\left(\varphi, r_{R}^{S}, \omega^{*}, q^{*}\right)=\mathbb{E}\left[\pi_{S}\right]^{m w}\left(r_{R}{ }^{S}, \omega^{*}, q^{*}\right)+\varphi p\left(q^{*}-\frac{q^{* 2}}{2 \beta}\right) .
$$

The results and findings are like the revenue-sharing contract with bank financing. The optimal wholesale price $\omega^{*}$ under the modified revenue-sharing contract with trade credit financing is lower than the production $\operatorname{costs} c_{S}$, what is inapplicable for the modified wholesale-price contract as it leads to the losses of the supplier for any retailer's order quantity $q$ and such contract will not be signed. On the other side, the optimal wholesale price in case of the modified wholesale-price contract is equal to the production costs, and its application instead of the optimal wholesale price of the modified revenue-sharing contract also leads to the dominance by the modified revenue-sharing contract as in this case the expected profit of the supplier deviates from zero. Based on comparison of supply chain's parties expected profits we can say that the supplier is able to redistribute the supply chain's profit through the parameter $\varphi$ choice for her benefit. Under the assumption made, the parameter $r_{R}{ }^{S}$ has no impact on the profit distribution as it is chosen that way that it is of the same value for both contracts.

Thus, for any $\left(\varphi^{0}, r_{R} S^{0}\right)$ from the set $D^{0}\left(\omega^{*}, q^{*}\right)=\left\{\left(\varphi^{0}, r_{R} S^{0}\right): 0<\varphi^{0}<\right.$ $\left.1,0<r_{R} S^{0}<1\right\}$ the inspected modified revenue-sharing contract with trade credit financing $\left(\varphi^{0}, r_{R} S^{0}, \omega^{*}\left(\varphi^{0}, r_{R} S^{0}\right), q^{*}\right)$ is conditionally coordinating according to the definition 4 .

\section{Comparison of the Modified Revenue-Sharing Contract with Trade Credit Financing and the Revenue-Sharing Contract with Bank Financing under the Assumption that Demand is Distributed as Uniformly}

As it is derived above, both contracts the revenue-sharing contract with bank financing and the modified revenue-sharing with trade credit financing are conditionally coordinating according to the definitions 2 and 4 respectively, thus, the 
supplier performs better in case of their application than in case of application of the wholesale-price contract with bank financing and the modified wholesale-price contract with trade credit financing respectively. But the results derived tell us only about the benefits of inclusion of supplier's revenue share parameter $\varphi$ and say nothing about the choice of supplier's interest rate parameter $r_{R} S$. To decide whether the modified revenue-sharing contract with trade credit financing is worth applying, the comparison between the contracts of the same type but implying different sources of financing (modified revenue-sharing contract with trade credit and revenue-sharing contract with bank financing) should be conducted.

For the ease of comparison and analysis, the expressions for the expected profits of the supplier, retailer, and the supply chain for these two contracts under the assumption of the demand being distributed as uniformly are presented in Table 5 .

Table 5. Expressions for expected profits of the supply chain and its parties for a product with demand distributed as uniformly

\begin{tabular}{|c|c|c|}
\hline Supply chain & Supplier & Retailer \\
\hline \multicolumn{2}{|c|}{ Modified revenue-sharing contract with trade credit financing } \\
\hline $\mathbb{E}\left[\pi_{S C}\right]^{\text {mrsh }}$ & $\mathbb{E}\left[\pi_{S}\right]^{\text {mrsh }}$ & $\mathbb{E}\left[\pi_{R}\right]^{\text {mrsh }}$ \\
\hline$p\left(q-\frac{q^{2}}{2 \beta}\right)-c q$ & $\begin{array}{c}\varphi\left(q-\frac{q^{2}}{2 \beta}\right)+ \\
+\left(\omega-c_{s}\right) q+ \\
\left.+\left(\omega+c_{R}\right) q-K_{R}\right) r_{R}{ }^{S}\end{array}$ & $-\left(\omega+c_{R}\right)\left(1+r_{R}{ }^{S}\right) q+K_{R} r_{R}{ }^{S}$, \\
\hline \multicolumn{2}{|c|}{ Revenue-sharing contract with } & bank financing \\
\hline \multirow{2}{|c|}[\pi_{SC}]{$^{r s h}$} & $\mathbb{E}\left[\pi_{S}\right]^{r s h}$ & $\mathbb{E}\left[\pi_{R}\right]^{r s h}$ \\
\hline$p\left(q-\frac{q^{2}}{2 \beta}\right)-c q-$ & $\varphi p\left(q-\frac{q^{2}}{2 \beta}\right)+$ & $(1-\varphi) p\left(q-\frac{q^{2}}{2 \beta}\right)-$ \\
$-\left(\left(\omega+c_{r}\right) q-K_{r}\right) r_{R}{ }^{B}$ & $+\left(\omega-c_{S}\right) q$ & $-\left(\omega+c_{R}\right)\left(1+r_{R}{ }^{B}\right) q+K_{R} r_{R}{ }^{B}$, \\
\hline
\end{tabular}

As can be seen, when the retailer decides to use bank financing there is a financial outflow in terms of the supply chain profit what makes it less than in case of trade credit financing. It is stated above that in both cases it is possible to achieve maximum of the retailer's expected profit through the decision on the order quantity $q$. But as it is seen, in case of trade credit financing the supplier is able to influence her expected profit and the expected profit of the supply chain through the implementation of a modified revenue-sharing contract and choosing the interest rate $r_{R} S$. Thus, the extended definition of a conditionally coordinating modified revenue-sharing contract with trade credit financing can be presented as follows.

Definition 5. If there is a modified revenue-sharing contract with trade credit financing $\left(\boldsymbol{\varphi}^{\prime}, \boldsymbol{r}_{\boldsymbol{R}} \boldsymbol{S}^{\prime}, \boldsymbol{\omega}^{\prime}, \boldsymbol{q}^{*}\right)$ that complies with conditions 1,2 and 3 of definition 4 , and the following inequation is true,

$$
\mathbb{E}\left[\pi_{S}\right]^{m r s h}\left(\varphi^{\prime}, r_{R}{ }^{S^{\prime}}, \omega^{\prime}, q^{*}\right)>\mathbb{E}\left[\pi_{S}\right]^{r s h}\left(\varphi^{\prime}, \omega^{\prime}, q^{*}\right),
$$

where $\omega^{\prime}=\omega^{*}\left(\varphi^{\prime}, r_{R} S^{\prime}\right)$, we can call it a conditionally coordinating contract. 
Thus, for a conditionally coordinating modified revenue-sharing contract $\left(\varphi^{\prime}, r_{R} S^{\prime}, \omega^{\prime}, q^{*}\right)$ the supplier's expected profit will be greater than in the case of a revenue-sharing contract with bank financing with parameters $\left(\varphi^{\prime}, \omega^{\prime}, q^{*}\right)$ which are achieved by selection of a parameter $\varphi$ and $r_{R}{ }^{S}$, which are denoted by $\left(\varphi^{\prime}, r_{R} S^{\prime}\right)$ in definition 5 and this set of parameters is denoted by $D^{\prime}\left(\omega^{*}, q^{*}\right)$.

As here we test the modified revenue-sharing contract with trade credit financing against the revenue-sharing contract with bank financing, i.e. we are interested in the impact of the presence of parameter $r_{R}{ }^{S}$ on the expected profit of the supplier under the modified revenue-sharing contract with trade credit financing, we assume that the parameter $\varphi^{\prime}$ is chosen the same for both contracts $\left(\varphi^{\prime m r s h}=\varphi^{\prime r s h}=\varphi^{\prime}\right)$.

Under the assumption of the supply chain parties acting rationally, the retailer's order quantity decision $q$, which is aimed at maximization of the retailer's profit, is affected by the contract parameters and will be different for the modified revenuesharing contract with trade credit financing and the revenue-sharing contract with bank financing, even if the optimal wholesale price $\omega^{*}$ used is the same.

For testing the modified revenue-sharing contract with trade credit financing to be conditionally coordinating according to the definition 5 , the fixed wholesale price $\omega^{f i x}$, which fulfills the condition 2 from definition $3\left(q_{R}^{* m r s h}\left(\varphi, r_{R}{ }^{S}, \omega^{*}\left(\varphi, r_{R}{ }^{S}\right)\right)=\right.$ $\left.q_{S C}^{* m r s h}\right)$, is set to be applied to each of the two contracts for further comparison of values of the supplier's expected profit under each of these contracts. Then, the expressions for the optimal order volume in case of the modified revenue-sharing contract with trade credit financing and the revenue-sharing contract with bank financing are as follows respectively:

$$
\begin{gathered}
q_{R}^{* m r s h}=\beta \frac{(1-\varphi) p-\left(\omega^{f i x}+c_{R}\right)\left(1+r_{R}^{S}\right)}{(1-\varphi) p}=\beta \frac{p-c}{p}, \\
q_{R}^{* r s h}=\beta \frac{(1-\varphi) p-\left(\omega^{f i x}+c_{R}\right)\left(1+r_{R}^{B}\right)}{(1-\varphi) p} .
\end{gathered}
$$

Substituting $\omega^{\text {fix }}$ with the expression (26) for the optimal wholesale price for the modified revenue-sharing contract derived previously, we get:

$$
q_{R}^{* r s h}=\beta \frac{p-c \frac{1+r_{R}{ }^{B}}{1+r_{R}}}{p} .
$$

According to the assumptions and statements made previously, the expressions for derivation of the supplier's expected profit under the modified revenue-sharing contract with trade credit financing and the revenue-sharing contract with bank financing can be presented as follows:

$$
\begin{aligned}
& \mathbb{E}\left[\pi_{S}\right]^{m r s h}= \varphi p\left(q_{R}^{* m r s h}-\frac{q_{R}^{* m r s h^{2}}}{2 \beta}\right)+\left(\omega^{f i x}-c_{s}\right) q_{R}^{* m r s h}+ \\
&+\left(\left(\omega^{f i x}+c_{R}\right) q_{R}^{* m r s h}-K_{R}\right) r_{R}^{S} \\
& \mathbb{E}\left[\pi_{S}\right]^{r s h}=\varphi p\left(q_{R}^{* r s h}-\frac{q_{R}^{* r s h^{2}}}{2 \beta}\right)+\left(\omega^{f i x}-c_{S}\right) q_{R}^{* r s h} .
\end{aligned}
$$


For the modified revenue-sharing contract with trade credit financing to be a conditionally coordinating contract according to the definition 5 , the supplier's expected profit under this contract $\left(\mathbb{E}\left[\pi_{S}\right]^{m r s h}\right)$ must be greater than the supplier's expected profit under the revenue-sharing contract with bank financing $\left(\mathbb{E}\left[\pi_{S}\right]^{r s h}\right)$, i.e.:

$$
\mathbb{E}\left[\pi_{S}\right]^{m r s h}-\mathbb{E}\left[\pi_{S}\right]^{r s h}>0 .
$$

After the substitution and transformation of the inequation, we get the following:

$$
\begin{gathered}
\varphi p\left(q_{R}^{* m r s h}-q_{R}^{* r s h}\right)\left(1-\frac{1}{2 \beta}\left(q_{R}^{* m r s h}+q_{R}^{* r s h}\right)\right)+ \\
+\left(\omega^{f i x}-c_{s}\right)\left(q_{R}^{* m r s h}-q_{R}^{* r s h}\right)+\left(\left(\omega+c_{R}\right) q_{R}^{* m r s h}-K_{R}\right) r_{R}^{S}>0 .
\end{gathered}
$$

Substituting $q_{R}^{* m r s h}$ and $q_{R}^{* r s h}$ with the expressions (29) and (31) derived previously, we obtain:

$$
\begin{array}{r}
\frac{\beta c}{p}\left(\frac{r_{R}^{S}-r_{R}^{B}}{1+r_{R}^{B}}\right)\left[\varphi p\left(\frac{2 p\left(1+r_{R}^{B}\right)-c\left(2+r_{R}^{S}+r_{R}^{B}\right)}{2 p\left(1+r_{R}^{B}\right)}\right)-c \frac{\varphi+r_{R} S}{1+r_{R} S}\right]+ \\
+\left(\beta c \frac{(1-\varphi)(p-c)}{p\left(1+r_{R}^{S}\right)}-K_{R}\right) r_{R}{ }^{S}>0
\end{array}
$$

Transforming the inequation (32), we get the following:

$$
\begin{gathered}
\quad \operatorname{pcr}_{R} S^{3}+r_{R} S^{2}\left(\varphi p\left(3 c-2 p\left(1+r_{R}^{B}\right)\right)+\frac{2 p K_{R}\left(1+r_{R}^{B}\right)^{2}}{\beta c}\right)+ \\
+r_{R}{ }^{S}\left(2 \left(\left(1+r_{R}^{B}\right)\left(p\left(1+r_{R}^{B}\right)(\varphi-1)+c\left(1+r_{R}^{B}(\varphi+2)\right)\right)+\right.\right. \\
\left.\left.+\varphi p\left(1-r_{R}^{B}\right)\left(c-p\left(1+r_{R}^{B}\right)\right)\right)-\varphi p c r_{R}^{B^{2}}-\frac{2 p K_{R}\left(1+r_{R}^{B}\right)^{2}}{\beta c}\right)+ \\
+r_{R}^{B}\left(\varphi p\left((p-c)\left(r_{R}^{B}-2\right)\right)-2 c\left(\varphi+r_{R}^{B}\right)\left(1+r_{R}^{B}\right)\right)<0 .
\end{gathered}
$$

Solution of the inequation (33) gives us the boarders of the supplier's interest rate values, within which the supplier's expected profit is greater under the modified revenue-sharing contract with trade credit financing than under the revenue-sharing contract with bank financing under the assumption of the supplier's revenue share $\varphi$ to be the same for both contracts.

Thus, for any $\left(\varphi^{\prime}, r_{R} S^{\prime}\right)$ from the set $D^{\prime}\left(\omega^{*}, q^{*}\right)=\left\{\left(\varphi^{\prime}, r_{R} S^{\prime}\right): 0<\varphi^{\prime}<1,0<\right.$ $\left.r_{R} S^{\prime}<1, r_{R} S^{\prime} \in\left(\underline{r_{R} S} ; \overline{r_{R} S}\right)\right\}$, where $\underline{r_{R} S}$ and $\overline{r_{R} S}$ are upper and lower boarders derived from the inequation (33), the inspected modified revenue-sharing contract with trade credit financing $\left(\varphi^{\prime}, r_{R} S^{\prime}, \omega^{*}\left(\varphi^{\prime}, r_{R} S^{\prime}\right), q^{*}\right)$ is a conditionally coordinating according to the definition 5 .

Up till now the supplier's revenue share $\varphi$ was assumed to be equal for both observed contracts, but unknown. The solution for the supplier's revenue share parameter $\varphi$ choice problem is done the following way. 
Recalling the expressions for the optimal order volume $q^{*}$ calculation for the revenue-sharing contract with bank financing (7) and the modified revenue-sharing contract with trade credit financing (24), it is seen that in case of the supplier's and bank's interest rates being equal the supplier can influence the order volume through the supplier's revenue share value $\varphi$ and the wholesale price value $\omega$, which optimal value in turn depends on $\varphi$ according to the expressions derived (refer to (9) and (26) respectively). Then, to obtain the restrictions for the supplier's revenue share $\varphi$ for the modified revenue-sharing contract the comparison between revenue-sharing contract with bank financing and the modified revenue-sharing contract with trade credit financing in terms of supplier's expected profit values is conducted. Here, in the contrast to the supplier's interest rate $r_{R} S$ restrictions derivation the optimal wholesale prices $\omega^{*}$ are assumed to be different and calculated as shown in (9) and (26) respectively, the supplier's interest rate $r_{R} S$ is assumed to be equal to the bank's one. Thus, we make a choice which type of financing the retailer should be chosen by the supplier corresponding to the desired revenue share without the interest rate impact.

The expressions for the supplier's expected profit values calculation in case of revenue-sharing contract with bank financing and modified revenue-sharing contract with trade credit financing are as follows respectively:

$$
\begin{gathered}
\mathbb{E}\left[\pi_{S}\right]^{r s h}=\varphi^{r s h} p\left(q^{r s h}-\frac{q^{r s h^{2}}}{2 \beta}\right)+\left(\omega^{r s h}-c_{S}\right) q^{r s h}, \\
\mathbb{E}\left[\pi_{S}\right]^{m r s h}=\varphi^{m r s h} p\left(q^{m r s h}-\frac{q^{m r s h^{2}}}{2 \beta}\right)+ \\
+\left(\omega^{m r s h}-c_{s}\right) q^{m r s h}+\left(\left(\omega^{m r s h}+c_{R}\right) q^{m r s h}-K_{R}\right) r_{R}{ }^{S} .
\end{gathered}
$$

Assume $r_{R}^{S}=r_{R}^{B}=r_{R}, \varphi^{m r s h}=\varphi^{r s h}=\varphi$ and substitute $q^{r s h}$ with $(30)$, $q^{m r s h}(29), \omega^{r s h}$ with (9) and $\omega^{m r s h}$ with (26) respectively:

$$
\begin{gathered}
\mathbb{E}\left[\pi_{S}\right]^{r s h}=\frac{\beta \varphi p}{2}\left(1-\frac{c}{p} \frac{1+r_{R}}{1+\varphi r_{R}}\right)^{2}, \\
\mathbb{E}\left[\pi_{S}\right]^{m r s h}=\beta \varphi \frac{(p-c)^{2}}{2 p}-K_{R} r_{R} .
\end{gathered}
$$

For the modified revenue-sharing contract with trade credit financing to be preferable in comparison to the revenue-sharing contract with bank financing for the supplier his expected profit value under the first contract should be greater than under the second one, i.e.:

$$
\mathbb{E}\left[\pi_{S}\right]^{m r s h}-\mathbb{E}\left[\pi_{S}\right]^{r s h}>0
$$

or

$$
\beta \varphi \frac{(p-c)^{2}}{2 p}-K_{R} r_{R}-\frac{\beta \varphi p}{2}\left(1-\frac{c}{p} \frac{1+r_{R}}{1+\varphi r_{R}}\right)^{2}>0 .
$$

After the transformation done, the following inequation is derived: 


$$
\begin{aligned}
\varphi^{3}\left(r_{R}(c-2 p)\right)+2 \varphi^{2}(p & \left.\left.r_{R}-1\right)+c-\frac{p K_{R} r_{R}^{2}}{\beta c}\right)+ \\
& +\varphi\left(2(p-c)-c r_{R}-\frac{4 p K_{R} r_{R}}{\beta c}\right)-\frac{2 p K_{R}}{\beta c}>0 .
\end{aligned}
$$

Solution of the inequation (34) gives us the restrictions for the supplier's revenue share values, within which the supplier's expected profit is greater under the modified revenue-sharing contract with trade credit financing than under the revenuesharing contract with bank financing and thus the trade credit financing is more preferable for the supplier if the supplier's interest rate coincides with the bank's one.

\section{Construction of a Coordinating Modified Revenue-Sharing Contract with Trade Credit Financing}

Data used for numerical example is given by Lin and He (2019).

The following information is available for a supply chain consisting of a supplier and a retailer: $p=\$ 4, c_{R}=\$ 0.11, c_{s}=\$ 0.89, c=\$ 1, r_{R}^{B}=9 \%$, demand for the realized product is a random variable and distributed as uniformly on the interval $[0 ; 100]$. There is no information about the retailer's cash available, but according to the assumptions made its value should fulfill the following condition: $\left(\omega+c_{R}\right) q-$ $K_{R}>0$, meaning that the retailer needs a short-term financing.

On the first step, the calculation of the optimal order volume value $q_{R}^{* m r s h}$ under the modified revenue-sharing contract with trade credit financing is done:

$$
q_{R}^{* m r s h}=\beta \frac{p-c}{p}=100 \frac{4-1}{4}=75 .
$$

On the second step, the calculation of the wholesale price $\omega=\omega^{*}$ according to (26) is done:

$$
\omega^{*}=c_{s}-c \frac{\varphi+r_{R} S}{1+r_{R} S}=0.89-\frac{\varphi+r_{R} S}{1+r_{R} S} .
$$

As it is required that $K_{R}<\left(\omega+c_{R}\right) q$, then

$$
K_{R}<75 \frac{1-\varphi}{1+r_{R} S}
$$

To estimate approximate universal value of $K_{R}$ the Solver (MS Excel) is used to calculate the maximum value of $\frac{1-\varphi}{1+r_{R}^{S}}$ for parameters from available set, consequently, the smallest possible value of $K_{R}$, which turns out to be $\$ 1.49$. For further calculations $K_{R}=\$ 1$ is taken.

On the third step, the expected profit of the supplier for both modified revenuesharing contract with trade credit financing and revenue-sharing contract with bank financing is calculated. For this purpose, the two following situations are considered.

1) $\varphi^{m r s h}=\varphi^{r s h}=\varphi$, i.e., the decision variable here is only $r_{R}{ }^{S}$.

According to (33), the restriction for the value of $r_{R} S$ to provide the supplier's expected profit to be greater under the modified revenue-sharing contract than under the revenue-sharing contract with bank financing looks as follows:

$$
4 \varphi r_{R}{ }^{3}+r_{R} S^{2}(0.1-22.88 \varphi)-r_{R}{ }^{S}(14.79 \varphi+7.03)-2.26 \varphi-0.02<0 .
$$


The simulation is done across different values of supplier's revenue share $\varphi$ and the inequation is solved with the respective values. The results show that for any value of supplier's interest rate $r_{R}{ }^{S}$ from available set under the assumption of the same values of $\varphi$ and $\omega$ for both contracts the supplier performs better applying the modified revenue-sharing contract with trade credit financing than the revenuesharing contract with bank financing.

Let us assume that $\varphi=15 \%$ and $r_{R}{ }^{S}=r_{R}{ }^{B}=9 \%$. Then the wholesale price $\omega^{*}$ equals to $\$ 0.83, K_{R}<\$ 58.49$, the supply chain, supplier's and retailer's expected profit values under the modified revenue-sharing contract with trade credit financing and revenue-sharing contract with bank financing are as follows respectively:

$$
\begin{gathered}
\mathbb{E}\left[\pi_{S C}\right]^{m r s h}=\$ 112.5, \mathbb{E}\left[\pi_{S}\right]^{m r s h}=\$ 16.79, \mathbb{E}\left[\pi_{R}\right]^{m r s h}=\$ 95.71, \\
\mathbb{E}\left[\pi_{S C}\right]^{r s h}=\$ 102.51, \mathbb{E}\left[\pi_{S}\right]^{r s h}=\$ 11.61, \mathbb{E}\left[\pi_{R}\right]^{r s h}=\$ 90.9 .
\end{gathered}
$$

As can be seen the trade credit financing application is profitable for every supply chain party and the supply chain itself.

The graphs of the expected profit of the supplier under the modified revenuesharing contract with trade credit financing and revenue-sharing contract with bank financing are constructed under the assumption of $\varphi=15 \%$ (Figure 3), $\varphi=50 \%$ (Figure 4) and $\varphi=80 \%$ (Figure 5), where horizontal axis stands for deviation of the supplier's interest rate $r_{R}{ }^{S}$ from the bank's interest rate $r_{R}{ }^{B}$.

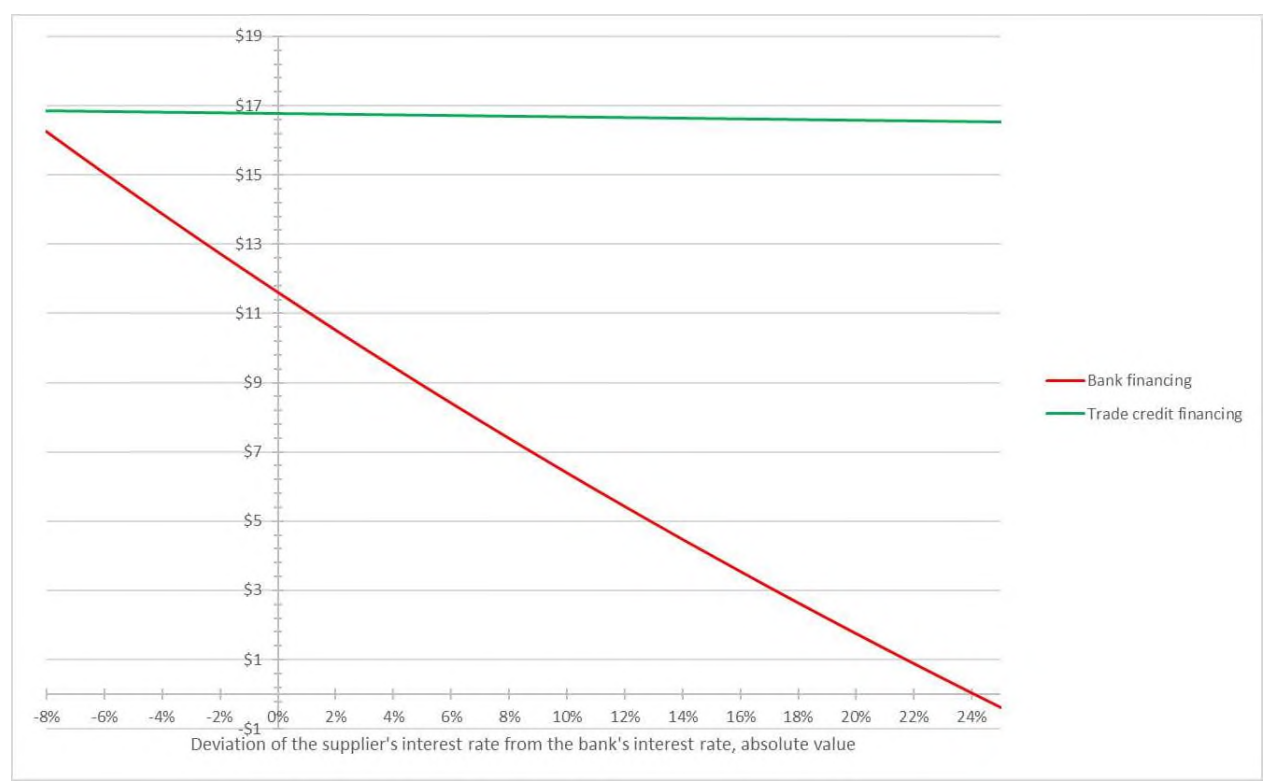

Fig. 3. Supplier's expected profit under different contracts with $\varphi=15 \%$ Source: authors own.

Actually, the reference point for supplier's interest rate parameter $r_{R} S$ choice is the bank's interest rate $r_{R}{ }^{B}$. It is stated that the supplier can choose any interest rate value and still gain more in case of trade credit financing provision, but it is 


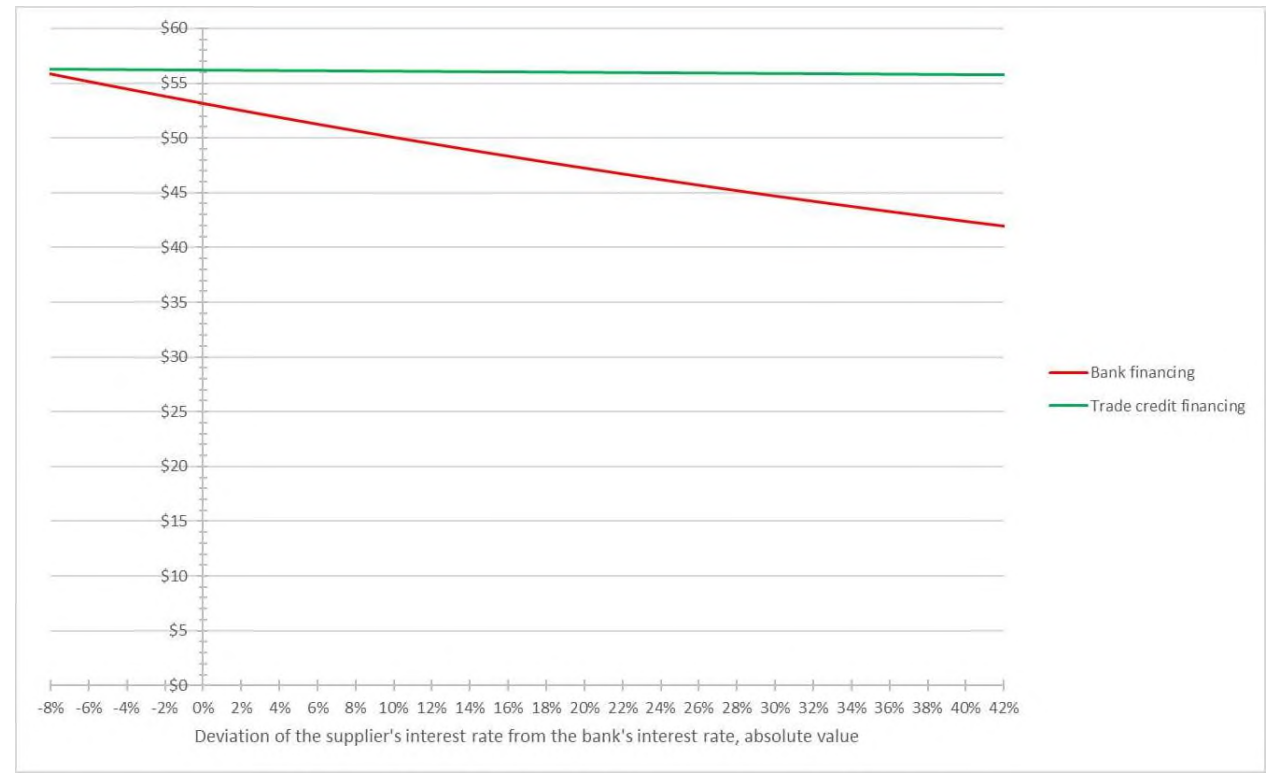

Fig. 4. Supplier's expected profit under different contracts with $\varphi=50 \%$. Source: authors own.

obvious that the retailer being aware of the bank's interest rate value will decline the proposed modified revenue-sharing contract if the supplier's interest rate is much greater than the bank's interest.

2) $r_{R}^{S}=r_{R}^{B}=r_{R}$, i.e., the decision about the source of financing is made and the decision variable here is $\varphi$.

According to (34), the restriction for the value of $\varphi$ to provide the supplier's expected profit to be greater under the modified revenue-sharing contract than under the revenue-sharing contract with bank financing looks as follows:

$$
-0.63 \varphi^{3}-5.28 \varphi^{2}+5.9 \varphi-0.08>0 .
$$

The inequation is true if the supplier's revenue share $\varphi$ belongs to the open interval $(0.014 ; 0.986)$. It means that the modified revenue-sharing contract with trade credit should be chosen if the desired level of supplier's revenue share value is greater than $1.4 \%$, but less than $98.6 \%$.

It is also empirically demonstrated that the increase in retailer's cash available has a dramatic impact on the supplier's revenue share value restriction. If instead of considering $K_{R}=\$ 1$ it is assumed to be, for example, $K_{R}=\$ 15$, what still follows the condition $K_{R}<\left(\omega+c_{R}\right) q$, then the inequation (34) looks as follows:

$$
-0.63 \varphi^{3}-5.29 \varphi^{2}+5.69 \varphi-1.2>0 .
$$

The inequation is true if the supplier's revenue share $\varphi$ belongs to the open interval $(0.294 ; 0.69)$, thus, the modified revenue-sharing contract with trade credit should be chosen if the desired level of supplier's revenue share value belongs to this open interval. 


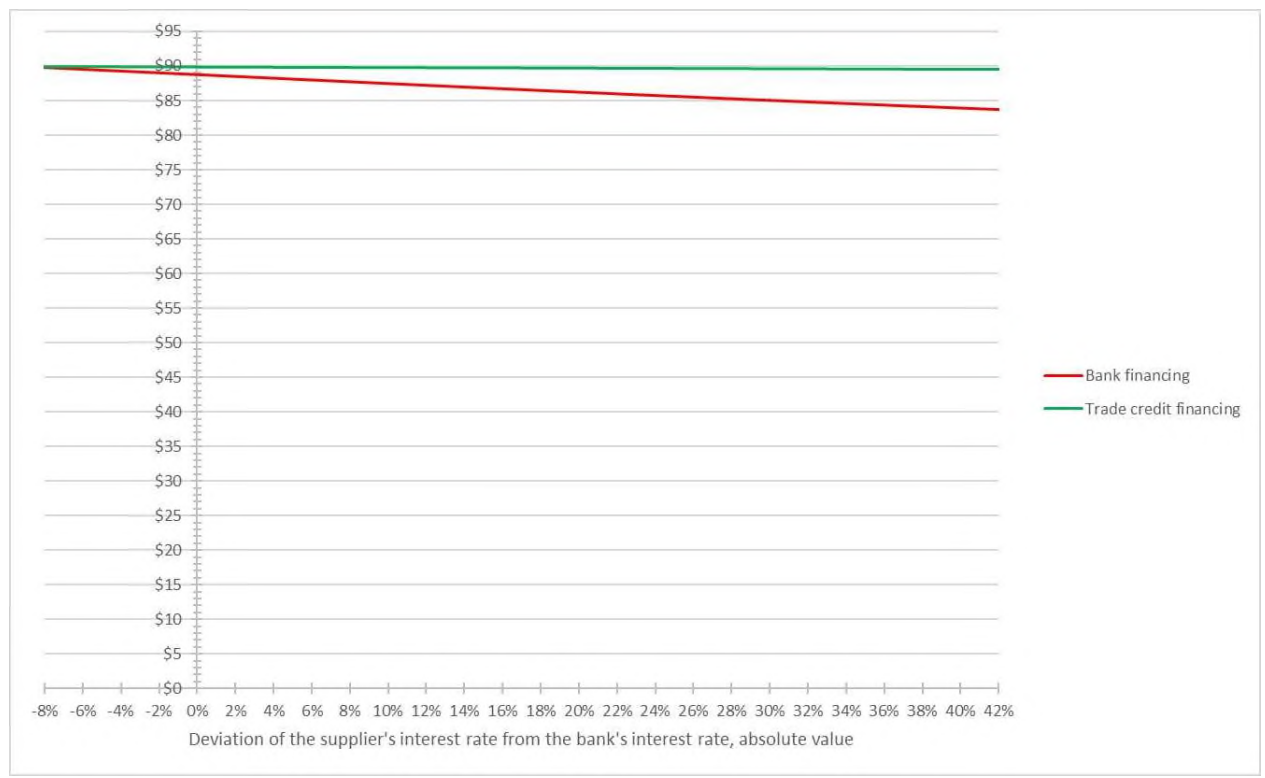

Fig. 5. Supplier's expected profit under different contracts with $\varphi=80 \%$. Source: authors own.

Let us assume that $K_{R}=\$ 15, r_{R}{ }^{S}=r_{R}^{B}=9 \%$ and $\varphi^{m r s h}=\varphi^{r s h}=0.5$. Then the wholesale price $\omega^{* m r s h}$ equals to $\$ 0.35, \omega^{* r s h}$ equals to $\$ 0.37$, the supply chain, supplier's and retailer's expected profit values under the modified revenuesharing contract with trade credit financing and revenue-sharing contract with bank financing are as follows respectively:

$$
\begin{aligned}
\mathbb{E}\left[\pi_{S C}\right]^{m r s h} & =\$ 112.5, \mathbb{E}\left[\pi_{S}\right]^{m r s h}=\$ 54.9, \mathbb{E}\left[\pi_{R}\right]^{m r s h}=\$ 57.6, \\
\mathbb{E}\left[\pi_{S C}\right]^{r s h} & =\$ 110.64, \mathbb{E}\left[\pi_{S}\right]^{r s h}=\$ 54.65, \mathbb{E}\left[\pi_{R}\right]^{r s h}=\$ 56 .
\end{aligned}
$$

As can be seen the trade credit financing application is profitable for every supply chain party and the supply chain itself if the supplier's revenue share lays in the restricted open interval.

Now assume that $K_{R}=\$ 15, r_{R}{ }^{S}=r_{R}^{B}=9 \%$ and $\varphi^{m r s h}=\varphi^{r s h}=0.15$. Then the wholesale price $\omega^{* m r s h}$ equals to $\$ 0.67, \omega^{* r s h}$ equals to $\$ 0.73$, the supply chain, supplier's and retailer's expected profit values under the modified revenuesharing contract with trade credit financing and revenue-sharing contract with bank financing are as follows respectively:

$$
\begin{aligned}
\mathbb{E}\left[\pi_{S C}\right]^{m r s h} & =\$ 112.5, \mathbb{E}\left[\pi_{S}\right]^{m r s h}=\$ 15.53, \mathbb{E}\left[\pi_{R}\right]^{m r s h}=\$ 96.98, \\
\mathbb{E}\left[\pi_{S C}\right]^{r s h} & =\$ 108.26, \mathbb{E}\left[\pi_{S}\right]^{r s h}=\$ 16.04, \mathbb{E}\left[\pi_{R}\right]^{r s h}=\$ 92.22 .
\end{aligned}
$$

As can be seen even though modified revenue-sharing contract with trade credit financing application is profitable for supply chain and the retailer, supplier gains less than under the revenue-sharing contract with bank financing. 
The graphs of the expected profit of the supplier under the modified revenuesharing contract with trade credit financing and revenue-sharing contract with bank financing are constructed under the assumption of $K_{R}=\$ 15$ (Figure 6).

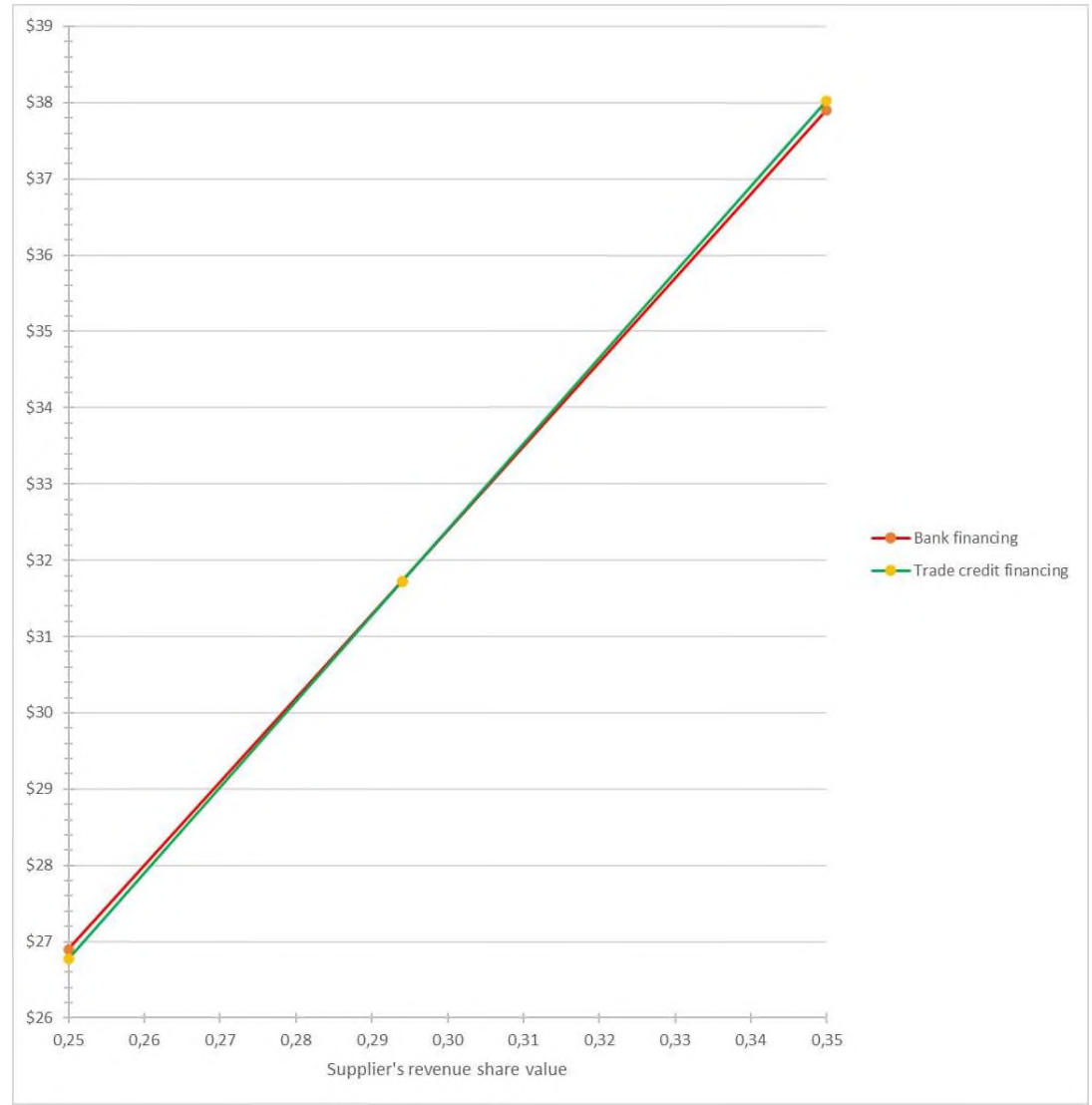

Fig. 6. Supplier's expected profit under different contracts with $K_{R}=\$ 15$. Source: authors own. 


\section{Conclusion}

In this paper, the supply chain coordination problem was studied. According to the problem stated the supply chain is coordinated when the supply chain profit is maximized, thus, the solution of the supply chain maximization problem was transformed into solving the problem of supply chain coordination and the coordination mechanism studied is contracts.

The contractual relationships between two risk-neutral supply chain parties: a supplier and a retailer were examined. It is assumed that the retailer does not have enough cash available to pay for the order immediately and needs short-term financing until the moment the demand is realized. In this case, a trade credit and a bank loan are considered as alternative short-term financing sources. A modelling of contracts is carried out using the game-theoretic approach, a contracting process is considered as a two-step game, where the supplier acts as a leader, i.e. takes the first step in making decisions, and the retailer - as a follower, i.e. makes decisions in response to supplier's decisions. The functions of winning are the functions of the expected profits, and the strategy here is the choice of contract parameters.

For the case when the retailer uses a bank loan as short-term financing source, a revenue-sharing contract with bank financing is considered. The parameters of this contract are identical to those of the traditional revenue-sharing contract, and the bank's interest rate is an external factor. According to the definition of a coordinating contract used, the parameters of the contract should be selected from the available set of values in such a way as to ensure the maximum of the expected profit values of the supply chain and its parties. It was demonstrated that the revenuesharing contract with bank financing does not coordinate the supply chain, because the maximum of supplier's expected profit is not achieved. However, it is possible to conditionally coordinate the supply chain, i.e. provide the maximum of supply chain and retailer's expected profit, and the supplier's expected profit to exceed the supplier's expected profit under a wholesale-price contract with bank financing for any values of the parameters belonging to the available set. Thus, a revenue-sharing contract with bank financing provides the supply chain profit maximization and is more profitable for both supply chain parties.

For the case when the retailer uses a trade credit as short-term financing, a modified revenue-sharing contract with trade credit financing is considered. In this case in addition to the parameters of a traditional revenue-sharing contract the interest rate proposed by the supplier is included. According to the definition of a coordinating contract used, the parameters of the contract including the supplier's interest rate should be selected from the available set of values in such a way as to ensure the maximum of the expected profit values of the supply chain and its parties. The same as for a revenue-sharing contract with bank financing, it was demonstrated that the modified revenue-sharing contract with trade credit financing does not coordinate the supply chain, due to the maximum of supplier's expected profit is not achieved. However, it is also possible to conditionally coordinate the supply chain, i.e. provide the maximum of supply chain and retailer's expected profit, and the supplier's expected profit to exceed the supplier's expected profit under a modified wholesale-price contract with trade credit financing (which is constructed similarly to a modified revenue-sharing contract by the supplier's interest rate inclusion as a parameter) for any values of the parameters belonging to the available set. Thus, a 
modified revenue-sharing contract with trade credit financing provides the supply chain profit maximization and is more profitable for both supply chain parties.

The application of the revenue-sharing mechanism for both types of retailer's short-term financing leads to an increase in the supplier's expected profit level. However, there is no information about the restrictions for the supplier's interest rate as a parameter and its impact on the supply chain, retailer's, and supplier's expected profit values. To solve this problem, a new definition of a conditional coordination was introduced for the modified revenue-sharing contract with trade credit financing. According to that, the contract should provide the maximum of supply chain and retailer's expected profit, and the supplier's expected profit to exceed the supplier's expected profit not only under a modified wholesale-price contract with trade credit financing, but also under a revenue-sharing contract with bank financing. It was proved that if the parameters comply with specified restrictions the modified revenue-sharing contract can conditionally coordinate the supply chain. It can be concluded that the modified revenue-sharing contract with trade credit financing provides the supply chain profit maximization and is more profitable for both supply chain parties. Thus, the construction of a modified revenue-sharing contract with trade credit helps to solve the problem of supply chain profit maximization under the assumption of the short-term financing necessity for one of the supply chain parties.

For testing the derived algorithm of coordinating contract construction, a simulated case was studied. The external parameters are taken from the article (Lin and $\mathrm{He}, 2019$ ), values of the contract's parameters were simulated where needed. In particular, different values of retailer's cash available were considered. Application of the algorithm derived previously showed that in case of fixed value of supplier's revenue share for a modified revenue-sharing contract with trade credit financing and a revenue-sharing contract with bank financing the supplier performs better applying any interest rate value from the available set under the modified revenuesharing contract with trade credit financing. In case of having fixed value of interest rate and retailer's cash available equal to $\$ 1$ for a modified revenue-sharing contract with trade credit financing and a revenue-sharing contract with bank financing the supplier performs better under the modified revenue-sharing contract with trade credit financing if the supplier's revenue share belongs to $(0.014 ; 0.986)$. At the same time if retailer's cash available equals to $\$ 15$ the supplier performs better under the modified revenue-sharing contract with trade credit financing if the supplier's revenue share belongs to $(0.294 ; 0.69)$. As a result, using the simulated case it was shown that it is possible to achieve conditional coordination and maximize the supply chain expected profit using the modified revenue-sharing contract with trade credit under the assumptions made.

As a result of this paper, the algorithm for derivation of the parameters of a coordinating and conditionally coordinating contracts under the assumption of the short-term financing necessity for one of the supply chain parties is developed. The algorithm can be used during negotiations between the supply chain parties to select such values which are suitable for both parties and the supply chain itself. Thus, the proposed solution for the supply chain coordination may be useful managerial tool in decision-making process while choosing the contract parameters. 
Coordinating Contracts as an Instrument of Supply Chain Profit Maximization 93

\section{References}

Abad, P. L., \& Jaggi, C. K. (2003). A joint approach for setting unit price and the length of the credit period for a seller when end demand is price sensitive. International Journal of Production Economics, 83(2), 115-122.

Arshinder, K., Kanda, A., and Deshmukh, S. G. (2011). A review on supply chain coordination: Coordination mechanisms, managing uncertainty and research directions. Supply Chain Coordination under Uncertainty, Springer-Verlag Berlin Heidelberg, 39-82.

Becker-Peth, M., Katok, E., \& Thonemann, U. W. (2013). Designing buyback contracts for irrational but predictable newsvendors. Management Science, 59(8), 1800-1816.

Berezinets, I. V., Zenkevich, N. A., Nikolchenko, N., \& Rucheva, A. (2019). Conditionally Coordinating Contracts in Supply Chains. In Frontiers of Dynamic Games (pp. 303336). Birkhäuser, Cham.

Bernstein, F., \& Federgruen, A. (2005). Decentralized supply chains with competing retailers under demand uncertainty. Management Science, 51(1), 18-29.

Cachon, G. P. (2003). Supply chain coordination with contracts. Handbooks in operations research and management science, 11, 227-339.

Cachon, G. P., \& Lariviere, M. A. (2005). Supply chain coordination with revenue-sharing contracts: strengths and limitations. Management science, 51(1), 30-44.

Cao, E., \& Yu, M. (2018). Trade credit financing and coordination for an emissiondependent supply chain. Computers \& Industrial Engineering, 119, 50-62.

Chiu, C. H., Choi, T. M., Yeung, H. T., \& Zhao, Y. (2012). Sales rebate contracts in fashion supply chains. Mathematical Problems in Engineering, 2012.

Chen, J. (2011). Returns with wholesale-price-discount contract in a newsvendor problem. International Journal of Production Economics, 130(1), 104-111.

Corbett, C. J., \& DeCroix, G. A. (1999). Shared savings contracts in supply chains. Anderson School at UCLA.

Dada, M., \& Hu, Q. (2008). Financing newsvendor inventory. Operations Research Letters, 36(5), 569-573.

Fabbri, D., Klapper, L.(2008). Market power and the matching of trade credit terms." World Bank Policy research working paper (4754).

Giannetti, M., Burkart, M., \& Ellingsen, T. (2011). What you sell is what you lend? Explaining trade credit contracts. The Review of Financial Studies, 24(4), 1261-1298.

Giannoccaro, I. and Pontrandolfo, P. (2004) Supply Chain Coordination by Revenue Sharing Contracts. International Journal of Production Economics, 89, 131-139.

Heydari, J., \& Asl-Najafi, J. (2018). A revised sales rebate contract with effort-dependent demand: a channel coordination approach. International Transactions in Operational Research.

Heydari, J., Choi, T. M., \& Radkhah, S. (2017). Pareto improving supply chain coordination under a money-back guarantee service program. Service Science, 9(2), 91-105.

Jaber, M. Y., \& Osman, I.H. (2006). Coordinating a two-level supply chain with delay in payments and profit sharing. Computers \& Industrial Engineering, 50(4), 385-400.

Mortimer, J.H. (2008). Vertical Contracts in the Video Rental Industry. The Review of Economic Studies, 75(1), 165-199.

Kim, J., Hwang, H., \& Shinn, S. (1995). An optimal credit policy to increase supplier's profits with price-dependent demand functions. Production Planning \& Control, 6(1), $45-50$.

Kouvelis, P., \& Zhao, W. (2012). Financing the Newsvendor: Supplier vs. Bank, and the Structure of Optimal Trade Credit Contracts. Operations Research, 60(3), 566-580.

Kouvelis, P., \& Zhao, W. (2016). Supply chain contract design under financial constraints and bankruptcy costs. Management Science, 62(8), 2341-2357.

Lee, C.H., \& Rhee, B. D. (2010). Coordination contracts in the presence of positive inventory financing costs. International Journal of Production Economics, 124(2), 331-339. 
Lee, C.H., \& Rhee, B.D. (2011). Trade credit for supply chain coordination. European Journal of Operational Research, 214(1), 136-146.

Li, L., Shubik, M., \& Sobel, M. J. (2013). Control of dividends, capital subscriptions, and physical inventories. Management Science, 59(5), 1107-1124.

Lin, T.T., \& Chou, J.H. (2015). Trade credit and bank loan: Evidence from Chinese firms. International Review of Economics \& Finance, 36, 17-29.

Lin, Q., \& He, J. (2019). Supply chain contract design considering the supplier's asset structure and capital constraints. Computers \& Industrial Engineering, 137, 106044.

Pasternack, B.A. (1985). Optimal pricing and return policies for perishable commodities. Marketing science, 4(2), 166-176.

Saha, S. (2013). Supply chain coordination through rebate induced contracts. Transportation Research Part E: Logistics and Transportation Review, 50, 120-137.

Shen, B., Wang, X., Cao, Y., \& Li, Q. (2019). Financing decisions in supply chains with a capital-constrained manufacturer: competition and risk. International Transactions in Operational Research, 27(5), 2422-2448.

Simchi-Levi, D., Kaminsky, P., Simchi-Levi, E., \& Shankar, R. (2008). Designing and managing the supply chain: concepts, strategies and case studies. Tata McGraw-Hill Education.

Taylor, T. A. (2002). Supply chain coordination under channel rebates with sales effort effects. Management science, 48(8), 992-1007.

Tsao, Y. C., Lee, P. L., Chen, C. H., \& Liao, Z. W. (2017). Sustainable newsvendor models under trade credit. Journal of cleaner production, 141, 1478-1491.

Tsay, A. A. (1999). The quantity flexibility contract and supplier-customer incentives. Management science, 45(10), 1339-1358.

Tsay, A. A., Nahmias, S., \& Agrawal, N. (1999). Modeling supply chain contracts: A review. In Quantitative models for supply chain management (pp. 299-336). Springer, Boston, MA.

Wang, C.X. (2002). A general framework of supply chain contract models. Supply Chain Management: An International Journal.

Wang, Y., Zipkin, P. (2009). Agents' incentives under buy-back contracts in a two-stage supply chain. International Journal of Production Economics., 120(1), 525-539.

Wei, J., \& Tang, J. (2013). Analysis on The Stackelberg game model and risk sharing based on buyback contract. Journal of Theoretical \& Applied Information Technology, 48(2).

Wei, G., Lin, Q., \& Qin, Y. (2013). A new buy-back contract coordinating dual-channel supply chain under stochastic demand. International Journal of Computer Science Issues (IJCSI), 10(1), 637.

Wong, W. K., Qi, J., \& Leung, S. Y.S. (2009). Coordinating supply chains with sales rebate contracts and vendor-managed inventory. International Journal of Production Economics, 120(1), 151-161.

Xiao, T., Shi, K., \& Yang, D. (2010). Coordination of a supply chain with consumer return under demand uncertainty. International Journal of Production Economics, 124(1), 171-180.

Xiao, S., Sethi, S.P., Liu, M., \& Ma, S. (2017). Coordinating contracts for a financially constrained supply chain. Omega, 72, 71-86.

Xiong, H., Chen, B., \& Xie, J. (2011). A composite contract based on buy back and quantity flexibility contracts. European Journal of Operational Research, 210(3), 559-567.

Xu, X.D., \& Birge, J.R. (2004). Joint production and financing decisions: Modeling and analysis. Working paper, Booth School of Business, University of Chicago.

Zhou, Y.W., Zhong, Y., \& Li, J. (2012). An uncooperative order model for items with trade credit, inventory-dependent demand and limited displayed-shelf space. European Journal of Operational Research, 223(1), 76-85. 